\title{
The influence of spectral composition on spring and autumn phenology in trees
}

\section{Brelsford, Craig}

2019-05-17

Brelsford, C , Nybakken, L, Kotilainen , T K \& Robson, T M 2019 , ' The influence of spectral composition on spring and autumn phenology in trees ' , Tree Physiology , vol. 39 , no. 6 , pp. 925-950 . https://doi.org/10.1093/treephys/tpz026

http://hdl.handle.net/10138/315655

https://doi.org/10.1093/treephys/tpz026

acceptedVersion

Downloaded from Helda, University of Helsinki institutional repository.

This is an electronic reprint of the original article.

This reprint may differ from the original in pagination and typographic detail.

Please cite the original version. 


\section{The influence of spectral composition on spring and autumn phenology in trees}

3 Author Affiliations:

$4{ }^{1}$ Organismal and Evolutionary Biology, Viikki Plant Science Centre (ViPS), Faculty of Biological and

5 Environmental Sciences, University of Helsinki, PO Box 65, 00014 Helsinki, Finland.

$6 \quad{ }^{2}$ Faculty of Environmental Sciences and Natural Resource Management, Norwegian University of Life Sciences,

$7 \quad 1432 \AA$ As, Norway

$8{ }^{3}$ Natural Resources Institute Finland, 20520 Turku, Finland

9

10 Article Type: Review

11

12 Corresponding Author: Craig Brelsford craig.brelsford@helsinki.fi

13

14 Keywords: bud break; leaf flush; spectral quality; sensory ecology, bud formation

15

16

17 


\section{Abstract}

Several recent reviews highlight the molecular mechanisms which underpin phenological responses to temperature and photoperiod, however these have mostly overlooked the influence of solar radiation and its spectral composition on these processes. For instance, solar radiation in the blue (B) and ultraviolet (UV) regions of the spectrum, as well as the red/far-red ratio (R:FR), can influence spring and autumn phenology. Solar radiation reaching the Earth changes diurnally and seasonally, however rising global temperatures, latitudinal range shifts and light pollution are likely to produce novel combinations of phenological cues for tree species. Here, we review the literature on phenological responses to spectral composition. Our objective was to explore the natural variation in spectral composition using radiative transfer models, and to reveal any species-specific or ecotype-specific responses relating to latitudinal origin. These responses are likely to be most pronounced at high latitudes where spectral composition varies most throughout the year. For instance, trees from high latitudes tend to be more sensitive to changes in R:FR than those from low latitudes. The effects of blue light and UV radiation on phenology have not been studied as much as those of R:FR, but the limited results available suggest both could be candidate cues affecting autumn leaf colouration and senescence. Failure of more-southern species and ecotypes to adapt and use spectral cues during northwards range shifts could result in mistimed phenology, potentially resulting in frost damage, reduced fitness and limited range expansion. Future areas for research should look to establish how consistently different functional types of tree respond to spectral cues, and identify photoreceptor-mediated mechanisms which allow plants to combine information from multiple light cues to coordinate the timing of phenological events. It should then be feasible to consider the synchronous or sequential action of light cues within a hierarchy of environmental factors regulating phenology. 


\section{Introduction}

Seasonal cues allow trees to time their bud burst and leaf-out to exploit conditions in spring and summer that are favourable for photosynthesis (Hänninen 1991, Augspurger 2009, Bennie et al. 2010). Another set of cues induce autumn leaf senescence and bud set as conditions become unfavourable again, and trees enter dormancy until the next spring (Lang et al. 1987, Hänninen 1995, Cesaraccio et al. 2004). Once sufficient chilling has occurred during dormancy in winter, rising temperature is the predominant cue affecting bud burst in tree species (Körner 2007, Caffarra and Donnelly 2010, Körner and Basler 2010). In addition, late-successional species are often sensitive to the increase in photoperiod during spring, more so than early-successional species (Basler and Körner 2012). On balance, temperature explains less variation in the timing of bud set and autumn leaf senescence, than it does for spring bud burst (Gallinat et al. 2015). Whilst for some species, average autumnal temperature or accumulated chilling (cold) temperatures have been found to largely predict the date of leaf senescence, photoperiod is a better predictor for other species, such as Fraxinus excelsior (Delpierre et al. 2009, Vitasse et al. 2011). Experimental manipulations have also confirmed that decreasing photoperiod to short days (SD) can serve as an autumnal cue for several tree species (Li et al. 2003, Welling and Palva 2006, Lagercrantz 2009).

Phenology of tree species has become a critical field of interest with respect to climate change and rising global temperatures (Bilger and Bugmann, 2018, Post et al. 2018, Richardson et al. 2018). The average date of bud-burst in temperate deciduous species is advancing (Menzel 2006, Körner and Basler, 2010), and the date of autumn leaf senescence is expected to occur later each year in accordance with rising temperatures (Menzel et al. 2006, Ibáñez et al. $2010^{\text {a }}$ ). However, relatively few studies have investigated the potential effect of climate change on autumn phenology (Gallinat et al. 2015, Panchen et al. 2015). Day length, temperature and numerous other environmental cues have been found to affect autumn phenology (Panchen et al. 2015 and references therein), leaving great potential for complex interactions between them. This is one reason why the timing of autumn senescence is more difficult than that of leaf out to explain with process-based models (Panchen et al. 2015, reviewed by Chuine and Régnière 2017). 

regression of bud burst against temperature. However, further increasing the complexity of these process-based bud burst models by attempting to simulate the physiological processes by which multiple cues interact, has todate failed to improve their power (Basler 2016, but see also Olsson and Jönsson 2014). Nevertheless, as our knowledge of the cellular, molecular and physiological mechanisms underlying the response to multiple cues continues to increase, we should be able to make models that are better able to predict tree phenology (Basler 2016, Chuine and Régnière 2017). Not only do changes in tree phenology have potential to create asynchrony with the timing of pollinators and seed dispersers, but they could also have implications for ecosystem processes such as carbon assimilation and leaf decomposition which are affected by the growing season length and the timing of leaf senescence (Cleland et al. 2007, Basler 2016). In turn, reliable models of these ecosystem processes are needed to incorporate feedbacks between vegetation and climate, as well as carbon sequestration into long-term forecasts of phenological events (Leinonen and Kramer 2002, Richardson et al. 2013).

Recently, several detailed reviews have examined the molecular mechanisms that allow trees to integrate cues from temperature and photoperiod to time their seasonality (Ding and Nilsson 2016, Singh et al. 2017, Maurya and Bhalerao 2017). Populus trichocarpa was the first tree to have its genome mapped, establishing Populus trees as a model tree species (Tuskan et al. 2006). The pathway that mediates growth cessation and bud dormancy through temperature and photoperiodism in Populus shows similarities with the pathway that regulates flowering in the other model plant species Arabidopsis thaliana (Böhlenius et al. 2006). In Arabidopsis thaliana, pathways triggered by blue/UV-A-detecting cryptochromes (CRYs) and R:FR-detecting phytochromes (PHYs) entrain the circadian clock (Somers et al. 1998, reviewed by Oakenfull and Davis 2017), controlling the activity of proteins such as CONSTANS (CO), which activate FLOWERING LOCUS T (FT) under long-days to induce flowering (Valverde et al. 2004). Similarly, in Populus, FT overexpression prevents growth cessation and bud set in response to SD conditions (Böhlenius et al. 2006), and temperature modulates the rate at which bud 

of a day, seasonally over the course of a year, as well as with latitude (Johnson et al. 1967, Smith 1982, Hughes 1984, Nilsen 1985). There is mounting evidence that these changes in spectral composition can influence spring and autumn phenology in tree species (Juntilla and Kaurin 1985, Linkosalo and Lechowicz 2006, Mølmann et al. 2006, Strømme et al. 2015, Opseth et al. 2016). Whilst the aforementioned reviews (Ding and Nilsson 2016, Singh et al. 2017, Maurya and Bhalerao 2017) summarise the molecular mechanisms underlying temperatureand photoperiod-mediated phenological responses in tree species, they do not consider the effects of spectral composition. The mechanistic responses associated with spectral cues for phenological processes are yet to be elucidated; but may have the potential to help us better predict and model future phenological responses.

Initial research identified an important role for PHYs in facilitating photoperiodic responses during the annual life cycle of trees (Olsen and Juntilla 2002, Mølmann et al. 2006; Taulavuori et al. 2010). However, the mechanism by which PHYs affect bud burst and bud set, as facilitated by changes in red:far-red (R:FR) light, has not been well defined. Although, both blue light and UV-B radiation (280-315 nm) have been shown to affect bud set (Mølmann et al. 2006, Strømme et al. 2015), it is not clear whether these effects act together with R:FR or not. It could be argued that just as blue and R:FR, detected by CRYs and PHYs, affect the circadian clock and these changes in spectral composition; 2) critically compare the methodology and results of studies examining 
specific responses across different latitudes, and 4) identify promising areas for future research into phenological responses to spectral composition, such as photoreceptor-mediated pathways which have yet to be elucidated, and candidate regions of the spectrum which may affect phenology but are yet to be thoroughly tested.

In compiling this review, we compared 21 studies which have investigated the effects of spectral composition on spring phenology (bud burst) (Table 1) and/or autumn phenology (leaf senescence or bud set) (Table 2). Studies demonstrating an effect of spectral composition on the bud burst of axillary shoots of non-tree species (Muleo et al. 2001, Girault et al. 2008) were also included in Table 1. Although this process differs from the spring bud burst of tree species, parallels in the effects of spectral composition and mechanisms involved may be relevant to tree species. Similarly, we included research on the effects of spectral composition on growth cessation (Juntilla and Kaurin, 1985, Tsegay et al. 2005) which has parallels with autumn phenology, and likewise the effects of light pollution on both spring and autumn phenology (Matzke et al. 1936, Saarala et al. 2013, ffrench-Constant et al. 2016). Studies were separated according to the regions of solar radiation they considered, either R/FR, blue light, or UV radiation. To allow a comparison of the different irradiances used in different studies, we give both the original units from each experiment and an estimate of irradiance following conversion to units of energy irradiance in $\mathrm{W} \mathrm{m}^{-2}$ based on the spectra provided in the studies (Tables 1,2 ), and using the photobiology package in R (Aphalo, Pedro J., ed., 2013-2018, www.r4photobiology.info ISSN 23433248, Helsinki; Aphalo 2015).

To exemplify how spectral composition varies throughout the year and across a latitudinal gradient, we modelled spectral composition using the radiative transfer model libRadtran which allows solar radiation at any location on the Earth's surface to be simulated, using solar angle and atmospheric conditions (following Emde et al. 2016 and Brelsford 2017, further details provided in SI). Our aim was to use these simulations to corroborate and elaborate upon measurements of natural variation in spectral composition from some of the reviewed studies, rather than to provide a comprehensive database of variation in spectral composition (Johnson et al. 1967, Smith 1982, Hughes et al. 1984, Chambers and Spence 1984, Lee and Downum 1991, López-Figueroa 1992, Ragni and D’Alcalà 2004). 


\section{Detection of changes in spectral composition}

Phytochromes (PHYs) are plant photoreceptors that detect red (R) and far-red (FR) light and compositional changes between these regions. In the dark, PHYs are synthesized in their red light-absorbing form (Pr, $\lambda=660 \mathrm{~nm})$, and upon exposure to light PHYs are converted to their far-red light absorbing form (Pfr, $\lambda=730 \mathrm{~nm}$, Smith 1982; Smith \& Morgan, 1983). The phytochrome equilibrium refers to the proportion of Pfr/Total Phy, and is thus reflective of the relative ratio of R:FR received, whereby high ratios of R:FR produce a higher phytochrome equilibrium $(\phi)$, due to the interconversion of PHYs in response to R and FR light (Holmes and Smith, 1977). The model species Arabidopsis thaliana, has five types of PHYs, whereby PHY A is the predominantly involved in detecting light/dark transitions, PHY B is the predominant R:FR photoreceptor, and PHYs C-E play a lesser role in R light sensing (Whitelam and Devlin 1997). The tree species Populus tremula, has one PHY A gene and two PHY B genes (Howe et al. 1998), whereas Picea abies has two genes resembling PHY A and PHY B (PHY N and PHY P) and one gene resembling PHY C/PHY A (PHY O, Clapham et al. 1998). In addition, phyA and phyB have an important role in regulating flowering in A. thaliana in response to photoperiodic changes, as well as changes in R:FR (Somers et al. 1998, Mockler et al. 2003).

There are two main groups of photoreceptors that mediate responses to changes in the blue/UV-A region: cryptochromes (CRYs) (max A at $\lambda=450 \mathrm{~nm}$ ) and phototropins (phots) (max A at $\lambda=450 \mathrm{~nm}$ ) (Pudasaini and Zoltowski 2013, Banerjee and Batschauer 2005, Briggs and Huala 1999). CRYs 1 and 2 have a role in entraining circadian rhythms, hypocotyl elongation, and seedling development, as well as the accumulation of flavonoids and anthocyanins (Shalitin et al. 2002, Casal 2000, Somers et al. 1998, Kubasek et al. 1992). Most notably in the context of this review, CRYs also mediate photoperiodic controls on flowering time together with PHYs in $A$. thaliana (Guo et al. 1998). However, in the tree species Picea abies, only partial CRY sequences have been found to date (Opseth et al. 2016). There is no evidence that phots modulate phenological responses, but they do maintain the circadian rhythm of oscillations in PSII operating efficiency under blue light (Litthaeur et al. 2015). 
163 Although PHYs are primarily R:FR photoreceptors, they do also have an absorption spectra in the blue/UV-A 164 spectral region (Ohgishi et al. 2004).

Many plant responses to UV-B radiation are mediated by the photoreceptor UV RESISTANCE LOCUS 8 (UVR8) which was first identified in Arabidopsis thaliana (Rizzini et al. 2011) but is thought to be ubiquitous among plants, having now been described in many species including bryophytes and the tree species Betula platyphylla (Soriano et al., 2018, Li et al. 2018). UVR8 regulates the accumulation of flavonoids in response to UV-B radiation, endowing protection against high irradiances of UV-B (Brown et al. 2005). It also has a role in mediating shade responses (Hayes et al. 2014), and possibly the accumulation of certain phenolic compounds in [Insert Table 1][Insert Table 2]

\section{Ecological role of R:FR light}

The most common calculation of the R:FR ratio is the ratio of $\lambda 660: 730 \mathrm{~nm}$ (defined by Smith 1982, used in studies shown in Table 1 and Table 2). During twilight hours, between dawn and sunrise, and between sunset and dusk (Goldstein 1976, Forsyth et al. 1995, Aphalo 2016), a drop in the ratio of R:FR due to the enrichment of FR light in the atmosphere is reported to occur (Figures 1 and 2, Smith 1982, Hughes et al. 1984, Chambers and Spence 1984). Other studies report a sharp brief increase in the R:FR ratio during sunrise and sunset but confirm that R:FR drops during twilight (Lee and Downum 1991, López-Figueroa 1992, Ragni and D’Alcalà 2004). Increased refraction of light entering the atmosphere during periods when the sun angle is between $-18^{\circ}$ and $0^{\circ}$, preferentially enhances longer wavelengths of the spectrum causing the reduction in R:FR during twilight (Holmes and Smith, 1977). The annual variation in twilight duration, (and thus the duration of a lowered R:FR ratio during twilight) increases at higher latitudes (Figures 1 and 2, Linkosalo and Lechowicz, 2006, Franklin and Whitelam 2007).

The involvement of PHYs in the detection of photoperiodism was originally inferred from the reversible effects of R and FR light on flowering when applied during night breaks (corresponding to a reversible change from the red $\mathrm{P}_{\mathrm{r}}$ to far-red $\mathrm{P}_{\mathrm{fr}}$-absorbing forms of phytochrome) (Kasperbauer et al. 1963, Fredericq 1964, Lane et al. 1965). For instance, plants that normally only flower under SD conditions, can be stopped from flowering 
by exposure to short night breaks of low-fluence R light, an effect which is reversed by subsequent exposure to

189

190

191

192

193

194

195

196

197

198

199

200

201

202

203

204

205

206

207

208

209

210

211

FR light (Kasperbauer et al. 1963, Fredericq 1964). Furthermore, mutants of Arabidopsis thaliana lacking

functional PHYs do not exhibit a photoperiodic flowering response (Guo et al. 1998, Mockler et al. 2002). Plants

growing at higher latitudes tend to exhibit greater sensitivity to photoperiodic responses, whereas photoperiodic

changes are less relevant for plants at low latitudes which tend not to display this capacity (Stinchcombe et al.

2004, Zhang et al. 2008, Way and Montgomery 2015). An alternative explanation is that there are latitudinal differences in how plants respond to R and FR light, whereby the length of the night is detected by short-day plants and southern ecotypes of plant species, whereas the FR-enriched twilight period at the end of the day is the determining factor for the response of long-day plants and northern ecotypes of plant species (Howe et al. 1996, Olsen 2010). This divergence in the use of R:FR-related cues allows those variations in the R:FR ratio associated with day-length, the time of year and latitude to be exploited by plants as a cue to time their phenology (Nilsen 1985).

\section{[Insert Figure 1]}

Figure 1. The change in daylength, twilight length and night length throughout the year 2017, along a latitudinal gradient of locations including Oulu $\left(65.01^{\circ} \mathrm{N}, 25.47^{\circ} \mathrm{E}\right)$, Helsinki $\left(60.17^{\circ} \mathrm{N}, 24.94^{\circ} \mathrm{E}\right)$ and $\operatorname{Madrid}\left(40.42^{\circ} \mathrm{N}\right.$, $3.70^{\circ} \mathrm{W}$ ), calculated from the photobiology package in $\mathrm{R}$ (Aphalo, 2016 ). Twilight length was defined as civil twilight, including solar angles from $-6^{\circ}$ and $0^{\circ}$.

\section{[Insert Figure 2]}

Figure 2. Modelled spectral ratios for $B: R$ and R:FR of incident solar radiation at solar angles of $0^{\circ}$ to $-6^{\circ}$ for civil twilight, and at solar zenith for noon. Locations along a latitudinal gradient shown in Figure 1.Values are shown for spring equinox, summer solstice, autumn equinox, and winter solstice. Here B:R defined as (410500/610-700nm, Johnson et al. 1967), R:FR Sellaro as(650 - 670/720 - $740 \mathrm{~nm}$, Sellaro et al. 2010) and R:FR Smith as ((655 - 665/725 - $735 \mathrm{~nm}$, Smith, 1982). Spectral irradiance was modelled using the radiative transfer 
model libRadtran following Emde et al. 2016, Brelsford 2017). Water column data was taken from Kållberg et al. (2005), ozone column thickness data from Experimental Studies Unit, Environment Canada (http://expstudies.tor.ec.gc.ca/e/index.htm).For twilight values, the solver sdisort was used, and for noon values, the solver disort was used. Further details provided in SI.

\section{R:FR effects on bud burst}

One of the most widely-cited examples of R:FR ratio affecting bud burst, is from an experiment where natural twilight in southern Finland was simulated in a growth chamber and compared with a twilight treatment enriched in FR light created using incandescent and fluorescence lights (Linkosalo and Lechowicz 2006). This low R:FR ratio treatment advanced bud burst of Betula pendula plantlets by 4 days compared with the control simulating natural twilight. Many responses of bud burst to R and FR are particular to specific species or populations (Erez et al. 1966, Mølmaan et al. 2006, Girault et al. 2008). Seedlings of Picea abies produce ecotype-specific responses of bud burst to R:FR (Mølmaan et al. 2006): a population from a northern latitude $\left(69^{\circ} \mathrm{N}\right)$ did not reach bud-burst when grown under $12 \mathrm{~h}$ of white light $\left(30-35 \mathrm{~W} \mathrm{~m}^{-2}\right.$, Phillips TLD $\left.15 \mathrm{~W} / 840\right)$ followed by $12 \mathrm{~h}$ daylight extension using R LED lights $(660 \mathrm{~nm})$ to provide $24 \mathrm{~h}$ total day length. However, the seedlings did achieve bud-burst when grown under $12 \mathrm{~h}$ day-length extension using FR LED lights (730 nm). Conversely, the $\%$ bud burst of populations from a more-southerly latitude exposed to the same treatments $\left(59^{\circ} \mathrm{N}\right.$ and $64^{\circ} \mathrm{N}$ ) was higher under R light than FR light. Such differences along a latitudinal cline show that some plants may be adapted to use changes in R:FR and spectral composition as cues to regulate the timing of bud burst.

Unlike these results, Erez et al. (1966) found that neither a FR treatment nor a combined R + FR treatment increased the percentage of bud burst in Prunus persica. It is interesting to consider whether this difference could be due to the latitude of origin of the plant species/ecotype studied. Bud burst in mid-latitude and northernlatitude ecotypes of Picea abies is more responsive to FR than that of southern ecotypes (Mølmaan et al. 2006), and likewise bud burst of Betula pendula of Finnish origin responds to FR treatment (Linkosalo and Lechowicz 

latitudes changes in spectral composition as opposed to changes in day length may regulate plant phenology, whereas at low latitudes the predominant cue is changes in day length rather than changes in spectral composition (Nilsen et al. 1985, Juntilla and Kaurin 1985, Lüttge and Hertel 2009).

The role of PHYs integrating light input into the circadian clock has been well studied in Arabidopsis thaliana, and there are several homolog regions of the circadian clock in the model tree species Populus tremula (Frewen et al. 2000, Kozarewa et al. 2010, Ibáñez et al. 2010 ${ }^{\text {b }}$. However, we still do not fully understand the possible mechanisms by which PHY photoreceptors mediate bud-burst in response to R:FR. Expression of PHY homologs PHY B1 and PHY B2 in Populus tremula, as well as concentrations of the signalling molecule abscisic acid (ABA), have been reported to increase during bud burst (Frewen et al. 2000). Similarly, PHY-Amediated FR-signalling has been reported to control expression of homolog regions of the circadian clock, such as LATE ELONGATED HYPOCOTYL (LHY) in Populus tremula (Kozarewa et al. 2010). In a separate study, expression of LHY delayed bud burst (Ibañez et al. 2010), suggesting that phytochrome-mediated expression of LHY, as well as ABA signalling, may be good candidate mechanisms to examine with respect to the response of bud burst to R:FR.

\section{R:FR effects on autumn phenology}

Only one study thus far has examined the effects of R:FR on autumnal leaf senescence (Lee et al. 2003). There, an experiment in Harvard Forest USA failed to detect a response of autumn leaf senescence to different R:FR ratios at different PAR irradiances in six woody species. However, a treatment that used a neutral shade cloth to reduce irradiance evenly across the spectrum delayed the decline in leaf chlorophyll content in all six species, and in anthocyanin content in five of the six species, throughout leaf senescence compared with all the R:FR treatments (Lee et al. 2003). In agreement with this, the leaf senescence and degradation of chlorophyll in leaves of Quercus robur was also delayed when subjected to shade (Cavender-Bares et al. 2000). Whilst the existing evidence suggests that R:FR ratios may not affect the rate of leaf senescence in woody species, there is 
262

263

264

265

266

267

268

269

270

271

272

273

274

275

276

277

278

279

280

281

282

283

284

285 opportunity to study the consistency of this response at different latitudes and in different species. We also recommend further research to identify the regions of the spectrum causing delayed leaf senescence under shaded conditions (Cavender-Bares et al. 2000, Lee et al. 2003).

Interestingly, R:FR has been shown to affect bud set in the gymnosperms Picea abies and Abies lasiocarpa, (Mølmaan et al. 2006, Opseth et al. 2016, Chiang et al. 2018) FR light delayed bud set most effectively in two experiments with Picea abies, however the ecotype-specific effects of FR and R light differed between the studies. Mølmann et al. (2006) demonstrated that FR $(730 \mathrm{~nm})$ was more effective at delaying bud set in northern $\left(69^{\circ} \mathrm{N}\right)$ and mid-range ecotypes $\left(64^{\circ} \mathrm{N}\right)$, whereas red light $(660 \mathrm{~nm})$ was more effective at delaying bud set in the southern ecotype $\left(59^{\circ} \mathrm{N}\right)$. Similarly, FR has been reported to delay the growth cessation of a northern ecotype more than a southern ecotype of Salix pentandra (Kaurin and Juntilla, 1985) However, using a very similar experimental set up to that of Mølmann et al. (2006), with equivalent spectral irradiance and temperature between treatments, Opseth et al. (2016) report that FR was consistently the more-effective light treatment at delaying bud set regardless of the latitudinal origin of the ecotype of Picea abies. Opseth et al. (2016) note that their inclusion of a fan to regulate temperature in the experimental compartments could have affected the microclimate of the experimental units, thus contributing to a difference in bud set from the previous experiment. It has been suggested that different mechanisms may regulate bud dormancy and bud set in gymnosperms and angiosperms (Olsen 2010), however given the paucity of studies, specifically on angiosperms, nothing definitive can be concluded.

Surprisingly, all of the above studies describing an effect of R and FR light on bud set express their treatments in terms of equal energy irradiance $\left(\mathrm{W} \mathrm{m}^{-2}\right)$. Photons of light at smaller wavelengths possess more energy per photon, thus when expressed in spectral irradiance (PPFD), the trees will be receiving different treatments in terms of spectral photon irradiance. This would mean that shorter wavelength treatments of equal energy irradiance will have a lower value of spectral photon irradiance. This unintended discrepancy in perceived irradiance between treatments could affect photoreceptor-mediated processes differently, and thus 
future experiments could be improved by ensuring equal treatments when expressed as spectral photon irradiance.

Of the PHYs that have been characterized in tree species, PHY A overexpression in Populus tremula causes insensitivity of apical-growth cessation to changes in photoperiod (Olsen et al. 1997) and the PHY B2 gene is coincident with a quantitative trait locus affecting bud set (Frewen et al. 2000). Beyond this, the specific role of individual phytochrome photoreceptors in tree species is not well defined, nor is the mechanism by which how they mediate bud set and growth cessation in response to R:FR ratio (Olsen 2010). Because northern ecotypes of woody species require prolonged FR treatment to delay bud set, it has been proposed they are most likely to have a predominantly PHY A-based system (Clapham et al. 1998, 1999, 2002). Whereas southern ecotypes of woody species typically respond to night breaks in a R:FR reversible manner, which is typical of the low-fluence R:FR reversibility of PHY B. However, most of the accumulation of transcripts from PHY genes in P. abies has been done after growth cessation and bud set (Opseth et al. 2016), making it difficult to distinguish whether transcript accumulation from PHY is a consequence of bud set rather than a causal factor. Although the effects of FR light delaying bud set in Picea abies are consistent among studies, its effects on ecotypes and species differs between studies (Table 1, Table 2). These inconsistencies further exemplify the need to identify the photoreceptor-mediated pathways which facilitate species- and ecotype-specific responses to R:FR signals.

\section{Natural variation in the blue region of the spectrum}

Blue light is most often defined as radiation within the spectral range of 400-500 nm (Table 1, Table 2). In a recent review, Olsen (2010) proposed that the ecological role of the phenological response to blue light remains unclear because clines in the relative proportion of blue light within global radiation received by plants in nature, e.g. over latitudinal gradients, have not been well described. Blue light is enriched during twilight 
603nm, Hulbert 1953, Johnson 2012). Measurements in northern Europe fail to show a latitudinal pattern in the mean monthly percentage of total radiation received as blue light throughout the growing season (Kvifte et al. 1983). However, a comparison of monthly means may not be the most ecologically-meaningful approach to detect patterns in blue light. For instance, both Johnson et al. (1967) and Hughes et al. (1984) describe blue light relative to the amount of red light (defined as 410-500/610-700nm by Hughes et al. 1984). The ratio of B:R has been shown to be highest in the mornings during twilight (measured in Loughborough, Leicestershire, U.K. 52.8 "N, 1.2"W by Hughes et al. 1984) and to rise again after sunset at dusk (originally measured in Washington, Kansas, 3949'22.4"N $97^{\circ} 02^{\prime} 28.5^{\prime \prime} \mathrm{W}$ by Johnson et al. 1967) (Figures 1,2). As with the R:FR ratio, these differences are due to the low sun-angle and long path-length of sunlight through the atmosphere; however enrichment of shorter wavelengths is due to the increasing proportion of scattered incident radiation. This means that the $\mathrm{B}: \mathrm{R}$ ratio will be more variable at higher latitudes, due to the larger variation in photoperiod and twilight hours throughout the year (Figure 1,2). The use of the B:R ratio to describe photoperiodic light signals during twilight may provide a physiologically-relevant light ratio as CRYs (blue light/UV-A photoreceptors) and PHYs (R:FR photoreceptors) in tandem regulate the timing of flowering in response to photoperiod (Guo et al. 1998). The irradiance of blue light is higher at low latitudes than high latitudes throughout the year (Figure 3); it also increases with total solar irradiance, photoperiod, and daily insolation.

326

327

[Insert Figure 3]

Figure 3. The modelled spectral photon irradiance for blue light $(420-490 \mathrm{~nm})$ and UV-A radiation (315400nm) at the locations given in Figure 1 along a latitudinal gradient. Spectral photon irradiance was modelled as described in Figure 2. Further details provided in SI.

\section{Blue light effects on bud burst}

Until recently, the effects of blue light on spring bud burst had only been studied in two tree species; the gymnosperm Picea abies and the angiosperm Prunus persica (Mølmann et al. 2006, Okie and Blackburn 2011). 
In Picea abies, a 6 week treatment of 12h white light and a day extension of a further $12 \mathrm{~h}$ blue light (460nm) did not induce bud burst in any of three provenances tested (Mølmann et al. 2006). This suggests that blue light is not involved as a cue for the detection of day length increasing during spring in Picea abies. For Prunus persica, blue light $(\lambda=475 \mathrm{~nm})$ produced the lowest $\%$ bud burst in both cultivars used in the experiment after 27 days, in comparison to red light $(\lambda=640 \mathrm{~nm})$ and yellow light $(\lambda=590 \mathrm{~nm})($ Okie and Blackburn 2011). However, the treatments used by Okie and Blackburn (2011) all differed in their irradiance, meaning that the percentage of bud burst also correlated with the total irradiance used in different treatments.

A recent experiment reported that blue light advanced bud burst in the dormant branches of Alnus glutinosa, Betula pendula and Quercus robur (Brelsford and Robson, 2018), in a comparison of broad spectrum treatments of equal PAR with a 12-h photoperiod which either included or excluded blue light. Interestingly, the time until 50\% bud burst was advanced most in the later successional Quercus robur (6.6 days), followed by A. glutinosa (6.3 days) then Betula pendula (4 days), supporting the suggestion that temperature is the primary cue for bud burst in early successional species (Basler and Körner 2012, Brelsford and Robson 2018). Blue light has been found to enhance photosynthesis in several different plant species (Sæbø et al. 1995, Goins et al. 1997; Matsuda et al. 2004; Košvancová-Zitová et al. 2009, Hogewoning et al. 2010). One potential hypothesis for the ecological role of blue light, is that it acts as a cue for conditions that are favourable for photosynthesis (e.g. sunny conditions which have higher irradiance of blue light), hastening bud burst and leaf out once other criteria such as suitable temperature have been met. One other proposed hypothesis is that enriched blue light during twilight may provide the cue (Figure 2; Johnson et al. 1967), and as the period of day length between twilight increases, this diurnal change in the timing of blue light is detected by the plant. It could be argued that this second hypothesis is less likely, because Mølmann et al. (2006) found that day-light extension using blue light did not produce bud burst in Picea abies. However, considering those few studies summarised above, it is hard to draw any strong conclusions on the effects of blue light on bud burst of tree species, especially given the unrealistic nature of the light treatments employed. A more-realistic treatment could be created, for instance, by partially attenuating blue light from received solar radiation, as has been done in studies of plant growth and 
metabolism (Siipola et al. 2015), rather than using monochromatic blue light or blue LEDs in controlled environments.

In Rosa sp. and another Rosaceae: Prunus cerasifera (Muleo et al. 2001, Girault et al. 2008), blue light also induced higher \% bud burst of vegetative shoots when grown under monochromatic blue light. The growth and number of preformed leaves in buds of Rosa sp. was higher under blue light (435 nm) after 12 days (Girault et al. 2008). After 15 days, the bud burst of axillary shoots was highest in Prunus cerasifera buds exposed to blue light $(\lambda=435 \mathrm{~nm})$ and a broad spectrum of white light (centred $\lambda=545 \mathrm{~nm})$, but lowest under red light $(660$ nm) (Muleo et al. 2001). Whilst the mechanisms underpinning the advance of bud burst in response to blue light in Betula pendula, Alnus glutinosa and Quercus robur remain to be determined, evidence from Rosaceae provides a clue as to potential future lines of enquiry.

Bud burst of vegetative shoots in response to blue light is in part controlled through the photoregulation of sugar metabolism (Girault et al. 2010). Given that the bud burst of many temperate deciduous tree species is also associated with sugar metabolite accumulation towards the buds (Catesson 1964, Barnola et al. 1986, Cottignies 1986, Kelner et al. 1993, Rinne et al. 1994), it could be interesting to investigate the effects of blue light on the sugar metabolism and spring bud burst in temperate deciduous tree species. Although PHYs absorb in both the B and R spectral regions (Ohgishi et al. 2004), Girault et al. (2008) do not rule out the possibility that CRYs could mediate the bud burst of vegetative shoots. Further work on gene expression and transcriptome analysis may begin to unravel which photoreceptors trigger this response.

\section{Blue light effects on autumn phenology}

Whilst a 6-week day-length extension with blue light (12 h white light $+12 \mathrm{~h}$ blue light $-460 \mathrm{~nm})$ did not induce bud burst in any of three provenances of Picea abies along a latitudinal gradient (Mølmann et al. 2006), the same experiment found that autumnal bud-set of Picea abies did respond to blue light. Experimental daylength extension with blue light delayed the number of days until 50\% bud-set by 4 days, 7 days and 3 days in 
384

385

386

387

388

389

390

391

392

393

394

395

396

397

398

399

400

401

402

403

404

405

406 provenances from latitudinal origins of $69^{\circ} \mathrm{N}, 64^{\circ} \mathrm{N}$, and $59^{\circ} \mathrm{N}$ respectively, but the time until $100 \%$ bud set was only delayed in the latter (by 7 days) (Mølmann et al. 2006). Using a very similar experimental design, with equivalent spectral irradiance and temperature treatments, Opseth et al. (2016) also found a delaying effect of blue light in Picea abies, whereby $100 \%$ bud set was induced after 30, 24 and 21 days (for population latitudinal origins of $69^{\circ} \mathrm{N}, 64^{\circ} \mathrm{N}$, and $59^{\circ} \mathrm{N}$ ) respectively. In both these experiments, R and FR light were more effective at delaying bud set than blue light (Table 2). However, it is not clear what an appropriate control for the effect of blue light would be: for instance, is the result just an effect of increased PAR irradiance per se acting as a day extension delaying bud set rather than a blue-light specific response? Interestingly, the expression of CRYs increased after bud set (Opseth et al. 2016), possibly suggesting the involvement of blue light and CRYs during autumn phenology in Picea abies.

There have been a few studies examining the effects of blue light on leaf senescence (Field et al. 2001, Lee et al. 2003, Table 2). Leaf senescence in response to blue light and photoperiod has been shown to occur in soya bean Glycine max (Meng et al. 2013, Zhang et al. 2008, Han et al. 2006). Meng et al. (2013) demonstrated a blue light-dependent interaction between cry2 and CIB 1, which regulates leaf senescence in Glycine max, and found that cry 2 mediated the rate of chlorophyll resorption during senescence. There is also a latitudinal cline in the photoperiodic control of flowering time among accessions of Glycine max (Zhang et al. 2008). Interestingly, cry 1 expression is strongly correlated with this latitudinal cline (Zhang et al. 2008). Lee et al. (2003) found no $\mathrm{R}: F R$ effect on chlorophyll resorption, or on the concentration of anthocyanins and flavonoids in leaves throughout autumn senescence, but the effect of blue light on these processes during autumn senescence has yet to be investigated. Given the role of CRYs in mediating the induction of flavonoids, anthocyanins and chlorophyll in response to blue light (Lin et al. 1996, Wade et al. 2001, Brelsford et al. 2018), the study of bluelight effects on these important processes during autumn senescence could be an interesting line of research. 


\section{Ecological role of $\mathrm{UV}$ radiation}

UV-B radiation varies naturally with latitude, elevation, season and time of day, as well as with differences in the ozone-layer's thickness, solar angle, and cloud cover across geographical regions (McKenzie et al. 2011; Bais et al., 2018). Generally, this leads to high UV-B irradiance close to the equator and with increasing elevation (Figure 4, Caldwell et al., 1980; Blumthaler et al., 1997; McKenzie et al., 2001a, 2001b).

The atmosphere is thought to be entering a period of recovery from the ozone depletion, leading incident UV-B radiation to return to similar or lower levels than those during the mid-late $20^{\text {th }}$ Century (Bais et al., 2018).

However, interactions with other climate changes still cause complex variation in the ozone column and localised severe depletion, as occurred in the spring of 2016 over the Nordic countries (Manney and Lawrence, 2016). Furthermore, periods of global dimming and global brightening would lead to changes in the proportion of diffuse to direct radiation reaching the biosphere through increases in aerosols and cloud cover (reviewed by Wild 2009). Such changes would reduce total UV radiation exposure but cause potentially large increases in the UV:PAR ratio due to the relative UV-enrichment of diffuse radiation (reviewed by Calbo and González 2005).

Depending on their exposure to UV-A and UV-B radiation, plants may produce stress and/or regulatory responses (Hideg et al. 2013, Verdaguer et al. 2017 and references there in). UV radiation is recognised as an important environmental cue modulating plant growth and development (Rozema et al. 1997; Jansen \& Bornman 2012). Often UV-A and UV-B radiation produce distinct effects on the accumulation of phenolic compounds, photosynthesis and growth (Verdaguer et al. 2017). One underlying reason for this may be that different photoreceptors are responsible for coordinating plant responses to wavelengths in the UV-A and UV-B regions (Lin 2000, Briggs and Christie 2002, Rizzini et al. 2011). In Arabidopsis thaliana, UV radiation has also been implicated in day-length sensing (Fehér et al. 2011). In addition, diurnal changes in leaf epidermal transmittance of UV radiation mediated by epidermal flavonoids (Barnes et al. 2016), are likely to be modulated by a spectral cue, of which UV radiation is the most likely candidate (Barnes et al. 2017).

[Insert Figure 4] 
432 Figure 4. The modelled spectral irradiance for UV-B $(280-315 \mathrm{~nm})$ at the given locations in Figure 1 across a 433 latitudinal gradient. Irradiance was simulated using the methods described in Figure 2. Further details provided 434 in SI.

\section{Little evidence that UV radiation is important for spring phenology}

There are only a handful published studies on the effect of UV radiation on plant phenology. Most of our knowledge originates from three field studies designed to test the effects of UV-B radiation on the seasonal phenology of the same clones of Populus tremula. In a modulated-UV-enhancement field experiment in Joensuu, Finland, Strømme et al. (2018a), found that a supplemental UV-B treatment (30\% increase compared with ambient) received in the previous growing season advanced the bud-burst date by 2.0 days in male (but not female) Populus tremula saplings. This effect was significant, but varied considerably from year to year, over three years of growth in plants that were 1-4 years old (Sivadasan et al. 2017, Strømme et al., 2015; 2018a).

In a separate experiment, the same clones were planted along an elevational gradient in Norway, with UVThis solar-UV-B manipulation found no significant effect of UV-B on bud burst (Strømme et al. 2018b). This may suggest that the effects of UV-B radiation on the bud burst of Populus tremula are small and short-lived. However, this is a response that has yet to be assessed more widely among species or functional types, being limited to one set of clones of Populus tremula.

\section{UV radiation advances autumn leaf senescence}

In the same experiments described above, 30\% UV-B-supplementation advanced autumnal bud set by 1 day in the first growing season (Strømme et al. 2015), but again, there was no effect during the two subsequent years except when axillary buds were removed, suggesting that hormonal regulation by ABA or auxin could be involved in this response (Sivadasan et al. 2017). Bud set in the first year of growth in the UVB-attenuation 
study, however, was advanced by 13 days under near-ambient UV-B compared with reduced UV-B radiation in Populus tremula at a high elevation site (830m a.s.1) but not at low altitude sites (237m and 575m a.s.1., Strømme et al. 2018b). The authors of this study suggest that increased UV-B irradiance at higher elevations could be the reason that an effect was only seen at the highest elevation in their study, however differences in UV-B irradiance along their elevation gradient are minute (from lowest elevation to highest elevation UV-B irradiance differs by less than $0.1 \mathrm{Wm}^{-2}$ in spring, and no difference in autumn), suggesting that other environmental factors at higher elevations may be interacting with UV-B radiation.

Leaf senescence in Fagus sylvatica is also accelerated in response to supplemental UV-B exposure. Zeuthen et al. (1997) grew 5-year-old seedlings of Fagus sylvatica in an open-top chamber in Denmark $\left(55.41^{\circ} \mathrm{N}, 12.06^{\circ} \mathrm{E}\right)$, with a UV-B treatment equivalent to $15 \%$ ozone reduction between $1^{\text {st }} \mathrm{July}$ and October 1993. In leaves exposed to supplemental UV-B radiation, the $F_{\mathrm{v}} / F_{\mathrm{m}}$ of PSII (maximal photosynthetic yield of photosystem II) and chlorophyll concentration both declined more rapidly than under near-ambient UV-B. Ultimately, leaf senescence was advanced by 12 days, a response that the authors attributed to stress. Further evidence for this conclusion was provided by the even faster autumn leaf senescence ( 27 days earlier), and decline in $F_{\mathrm{v}} / F_{\mathrm{m}}$, and chlorophyll degradation, produced when a tropospheric-ozone treatment was combined with supplemental UV-B radiation (Zeuthen et al. 1997).

Strømme et al. $(2015,2018)$ suggest possible mechanisms by which UV-B radiation could affect bud burst and bud set in tree species. UV-B radiation has been reported to down regulate the plant hormone gibberellic acid (GA) which is involved in apical bud formation in Salix pentandra and Populus tremula. (Olsen et al. 1995a, b, 1997a, b, Mølmann et al. 2006). This presents a possible explanatory mechanism for the delay in budset reported above, and the difference between the response of intact clones and those with lateral buds excised. UV-B detection by Arabidopsis thaliana antagonises shade-avoidance responses mediated by auxin together with GA (Hayes et al. 2014). If GA in Populus tremula is affected by UV-B radiation through a similar signalling pathway to that of Arabidopsis thaliana, it is possible that a UV-B-attenuation treatment, like that of Strømme et al. (2018), would interfere with this response. Increased ABA concentrations in the apical meristem 
481

482

483

484

485

486

487

488

489

490

491

492

493

494

495

496

497

498

499

500

501

502

503

504

are associated with autumnal bud formation in Populus during short days (Ruttink et al. 2007), hence bud formation in Populus tremula may be affected by UV-B radiation through increases is ABA.

Similarly to the effects of UV-B radiation on bud burst, its reported effects on bud set tend to be small and short-lived (not beyond one season). Furthermore, many other studies have reported long-term acclimation to UV-B radiation treatments. For instance, 3 years of supplemental UV-B treatment produced no difference in growth or photosynthesis of Psuedotsuga menziesii (Bassman et al. 2002). Likewise, responses of leaves to UV-

B radiation often decrease over time (Kakani et al. 2004, Klem et al. 2012, Robson and Aphalo 2012), partly due to the production of UV-B-absorbing phenolic compounds that reduce transmittance of UV-B radiation to the mesophyll (e.g. Jansen et al. 1996). Such UV-B protection also develops in buds and bud scales (Sivadasan et al. 2015) and could moderate the true dose of UV-B radiation received by inside the bud in spring-phenology experiments. UV-B screening by phenolics in buds of Populus tremula was not checked in the attenuation study by Strømme et al. (2018), but the relative composition of phenolic compounds in leaves did change between plants grown under their different treatments. In this way, we might also expect that the diminishing effects of UV-B radiation on bud burst and bud set may be due to Populus tremula acclimating to UV-B radiation.

[Insert Figure 5]

Figure 5. A schematic representing the different environmental cues which can affect (A) spring bud burst and (B) autumn senescence in tree species, based on mean and median responses in Tables 1 and 2 (further details in Tables S1 and S2). For spring bud burst, chilling during dormancy, forcing temperature and light-derived cues such as photoperiod, irradiance and spectral composition can influence spring bud burst. Phytochrome (PHY) expression can be associated with bud burst (Frewen et al. 2000), although not directly in response to R:FR. Temperature, photoperiod and spectral composition have been shown to influence bud set and autumn leaf senescence. Expression of phytochromes (PHYs) and cryptochromes (CRYs) has been shown to increase during bud set (Frewen et al. 2000, Opseth et al. 2016), suggesting that either twilight or end-of-day (EOD) blue light may also play a role in regulating bud set. 
506 Future research on responses to spectral composition

507 Given that autumn leaf senescence is influenced by environmental cues other than temperature to a greater

508

509

510

511

512

513

514

515

516

517

518

519

520

521

522

523

524

525

526

extent than spring phenology, it is surprising that relatively few studies have considered spectral quality in this context. Lee et al. (2003) found that shading reduced the rate of chlorophyll and anthocyanin degradation in several tree species, and yet R:FR had no effect. This leaves open the possibility that regions of the spectrum other than R and FR could act as cues for these responses. For instance, supplemental UV-B radiation can advance leaf senescence, e.g in Fagus sylvatica (Zeuthen et al. 1997), and also promotes the accumulation of anthocyanins in leaves (Hoch et al. 2001). Blue light is another candidate cue, shown to advance leaf senescence in Glycine max through a cry-dependent response (Meng et al. 2013), and to enhance anthocyanin accumulation in leaves (Hoch et al. 2001).However, experimental studies that use realistic manipulations spectral composition are needed to properly consider the role of these regions as phenological cues, in order to quantifying the magnitude of responses and to assess their importance relative to other environmental cues.

The view that green light $(500-600 \mathrm{~nm})$ is less important than other wavelengths of the spectrum still persists to some extent (Smith et al. 2017). However, green light not only contributes to photosynthesis deep within canopy profiles (Murchie and Horton 1998, Sun et al. 1998, Nishio 2000), but also conveys information to plants about their light environment producing signalling cascades (Bouly et al. 2007). With respect to its potential involvement in phenological processes, green light has been shown to inhibit blue light/UV-A responses detected by CRY photoreceptors (Banerjee et al. 2007, Bouly et al. 2007, Sellaro et al. 2010). As CRYs have been implicated in regulating phenological responses, we should also consider the role of green light and its natural variation in tree phenology. 


\section{Understanding the integration of multiple spectral cues}

528 Other fields of plant photobiology, have been building an integrated picture of photoreceptor crosstalk, 529 and how plants combine multiple light signals. For example, PHYs and CRYs have antagonistic effects on the 530 light input into the circadian clock and flowering in Arabidopsis thaliana (Somers et al. 1998). UV-B radiation 531 perceived by UVR8 delays flowering time in Arabidopsis thaliana (Dotto et al. 2018), and inhibits the low

532 R:FR-mediated acceleration of flowering which is characteristic of shade avoidance in Arabidopsis thaliana 533 (Hayes et al. 2014). There is potential to investigate similar interactive effects between different regions of the solar spectrum on the spring and autumn phenology of tree species, and this would be more ecologically relevant than looking at individual regions in isolation. We now know that both CRYs and PHYs affect bud set in tree species (Böhlenius et al. 2006, Opseth et al. 2016). Furthermore PHYs, CRYs and UVR8 have all been shown to interact with candidate signalling molecules which can affect phenology such as the plant hormones GA and ABA (Frewen et al. 2000, Xu et al. 2010, Song et al. 2013, Hayes et al. 2014, Dotto et al. 2018). These plant hormones provide a promising focus of study in attempting to reveal the mechanisms by which different light cues and their corresponding photoreceptors combine information to control the timing of leaf and bud

541 phenology 
544 The mean and median effect sizes of enriched blue light and twilight R:FR on spring bud burst were of a similar bud burst per hour photoperiod increase, and 4-6 days earlier bud burst in treatments of enriched blue light and twilight R:FR Table 3, S1 and S2). In comparison, the mean effect sizes of chilling and forcing temperatures were 1.0 days advanced bud burst per 1 chilling day increase (Table 3), and 2.0 days advanced bud burst per 1 ${ }^{\circ} \mathrm{C}$ increase in forcing temperature (Table 3). Considering the relatively large responses to an increase in chilling days or forcing temperatures compared with photoperiod and spectral composition, we might expect variation in these cues to have a greater potential to affect the bud burst of trees (Fig S1). However, comparing the mean and median effect size does not take into account all of the different treatment conditions used in these experiments. Like photoperiod, the larger variation in spectral composition at higher latitudes, and the population specific responses seen in these regions, could be but one reason why current process-based models do not perform well at high latitudes in continental scale models (Olsson \& Jönsson 2013, Basler 2016). It has been suggested that the effects of photoperiod and chilling on bud burst and leaf-out can compensate for each other, i.e. when chilling is low, there is a greater effect of photoperiod and vice versa (Flynn and Wolkovich 2018). In this sense, different environmental cues e.g. chilling, temperature, photoperiod, irradiance etc. are likely to interact and in doing so affect the treatment response. This likelihood supports a call for future experiments to investigate the interactive effects and importance of these environmental cues and spectral composition. Further understanding of how these environmental cues integrate across different latitudes, will be integral to predicting how trees will adapt and migrate in response to climate change.

We still lack the experimental evidence to rank the environmental drivers of bud set and leaf senescence

The only experimental studies on bud set in response to spectral composition, temperature and photoperiod are on Populus tremula and Picea abies (Table S2). In comparison, for Alnus glutinosa and Quercus robur we were 
unable to find any studies describing the environmental cues which affect their bud set. For both Betula pendula and Picea abies, SD conditions induce bud set, and northern ecotypes are most sensitive to changes in photoperiod (Ekberg et al. 1979, Li et al. 2003). Interestingly, in Betula pendula temperatures between $15-18{ }^{\circ} \mathrm{C}$ have been shown to advance bud set, whilst higher temperatures $>21^{\circ} \mathrm{C}$, and low temperatures between 9-12 ${ }^{\circ} \mathrm{C}$, delay bud set (Li et al. 2003). This indicates adaptation to an optimal temperature range for bud set in Betula pendula, complicating forecasts of how climate change could affect bud set in Betula pendula. Similarly, temperature and photoperiod have an interactive effect on bud-set in Populus tremula, whereby short days, cold nights and warmer days have all been shown to hasten bud set (Rhode et al. 2011).

The biological effect sizes of FR were much greater on bud set than for bud burst. The mean and median percentage of bud set after exposure of trees to end of day FR was $2.4 \%$ and $0 \%$ (Table S2). There is little evidence to suggest that UV radiation strongly affects bud set, which had a mean and median effect of 2.9 days and 0 days advanced bud set. Day extension with blue light delayed bud set, but was not able to prevent it, as plants reached $100 \%$ bud set by the end of the experiments (Table S2). The mean and median effect of UV-B on bud set is also negligible (2.9 days delay, and 0 days). There are insufficient studies to compare the effects of FR light against other environmental drivers affecting bud set, but since in some cases FR is able to prevent bud set altogether this would suggest that FR is potentially an important environmental cue regulating bud set.

The two experimental studies we found investigating the effects of spectral composition on autumn leaf senescence in trees (Table 2), remain too few to allow us to make generalisations (Gallinat et al. 2015), especially since we were unable to compare the size effects of spectral composition against other environmental cues affecting leaf senescence in the same species. Nevertheless, in experimental studies, both a shortening photoperiod and decreasing temperatures have been shown to advance leaf senescence in Populus tremula (Fracheboud et al. 2009). However, a more recent study comparing two common gardens of Populus tremula, 
592

593

594

595

596

597

598

599

600

601

602

603

604

605

606

607

608

609

610

611

612

613

614

615

616

found the difference in photoperiod between the locations of the two common gardens not to have an effect on leaf senescence (Michelson et al. 2018). The authors suggest that another light-derived signal, for instance chloroplast-signalling related to a decline in photosynthetic performance may trigger senescence. The effects of UV-B could be advancing the leaf senescence of Fagus sylvatica in a similar manner, triggered by a decline in photosynthetic performance (Zuethen et al. 1997). If accumulated photodamage through a growing season can advance leaf senescence, then daily insolation could be a valid parameter to include when examining the main environmental drivers of leaf senescence (Liu et al. 2016). A meta-analysis of studies on leaf senescence found that overall, the most important factors affecting leaf senescence in the northern hemisphere were temperature in October, accumulated cold-degrees, latitude, photoperiod, then lastly, precipitation (Gill et al. 2015), but it did not consider daily insolation or spectral cues. The main cues differed between high and low latitudes.

Temperature alone may be a reasonable predictor of $50 \%$ leaf senescence at low latitudes $\left(\mathrm{R}^{2}=0.49\right.$ across both high and low latitudes, Gill et al. 2015). In contrast, the date of leaf senescence at higher latitudes has remained fairly constant between 1993-2010 despite large changes in temperature (Jones et al. 2012, Gill et al. 2015), possibly due to a photoperiodic constraint (Way and Montgomery, 2014). However, the most important environmental factor associated with a change in leaf colour, as opposed to 50\% senescence, was latitude (Gill et al. 2015). This begs the question, how are changes in leaf colour and final leaf senescence/leaf fall related, and why is this relationship different at different latitudes? As trees from higher latitudes tend to demonstrate greater sensitivity of bud burst and bud set to changes in spectral composition, it would also be of great interest to test the response of leaf colour as well as leaf senescence to changes in spectral composition. Understanding the environmental cues which govern both bud set and leaf senescence will be important if we are to predict whether these two aspects of autumn phenology will respond differently to climate change (Way, 2011).

\section{Interaction of phenology with climate change and with other ecosystem processes}

Could northward range shift due to increasing average temperatures in the northern hemisphere be limited by spectral composition? It has been reported that bud burst in tree species from southern latitudes is more 
617

618

619

620

621

622

623

624

625

626

627

628

629

630

631

632

633

634

635

636

637

638

639

640

641

sensitive to changes in photoperiod, and more northern ecotypes leaf out earlier when grown in common garden experiments (Kriebel et al. 1957, Olson et al. 2013, Zohner et al. 2016, Osada et al. 2018). Many other studies show the opposite effect, that is that spring bud burst of more northern ecotypes are more sensitive to changes in photoperiod, and that more southern ecotypes tend to leaf out earlier when grown in common garden experiments (Vaartaja 1959, Myking and Heide 1994, Robson et al. 2013, Review by Way and Montgomery 2015, Cooper et al. 2018). According to the latter, photoperiod has been proposed to limit the poleward range shift in tree species (Way and Montgomery, 2015), and may be contributing to a decline in the advance of spring bud burst in response to increasing global temperatures (Fu et al. 2015). Like photoperiod, spectral composition becomes more variable at higher latitudes. Given that most of those tree species and ecotypes tested from high latitudes exhibit greater sensitivity in changes to spectral composition than those from low latitudes, we may expect the importance of spectral composition as a cue for timing phenology to be greater at higher latitudes. Failure of more-southern species and ecotypes to adapt and use these cues during northwards range shifts could result in mistimed phenology in either spring or autumn, which can in turn cause frost damage and potentially reduce fitness and limit range expansion (Hänninen 1991, Chuine and Beaubien 2008). However, factors such as ozone, water vapour and aerosols in the atmosphere affect spectral composition (Emde et al. 2016), and vary by location around the globe. This means that it's possible for two locations that are far apart at different longitudes, but on the same latitude to have different spectral composition but the same photoperiod. This gives all the more reason for studies on both changes in spectral composition and trees responses to these changes, to be expanded beyond Europe and North America (Tables 1 and 2) to other regions and biomes around the globe.

Another driver of autumn leaf senescence is drought (Chen et al. 2015, Estiarte and Peñuelas 2015, Xie et al. 2015). Under climate change, drought is expected to increase, especially in mid-latitude and sub-tropical dry regions (Trenberth et al. 2014), with a poleward expansion of subtropical dry zones (Seager et al. 2010). An increase in drought has been reported to advance leaf senescence in several species (Chen et al. 2015, Estiarte and Peñuelas 2015), however moderate drought can delay leaf senescence (Xie et al. 2015). To varying degrees, drought is expected to advance leaf senescence whilst increasing temperatures under climate change are 
642 expected to delay leaf senescence. The combined effects of drought and spectral cues on phenology are yet to be 643 explored. Given the higher UV-B irradiances found at mid-low latitudes compared with high latitudes, and the 644 concurrent higher occurrence of drought, it would be of interest to investigate the interactions between UV-B 645 radiation and drought on leaf senescence for tree species growing at mid-to-low latitudes.

Shifts in the timing of canopy development can bring about a change of $20 \%$ or more in temperate and

647

648 boreal forest net photosynthetic production (Myneni et al. 1997). A study in Harvard Forest found that \pm 10 days variation in bud-burst date led to $\pm 5 \%$ difference in annual gross primary productivity (Migliavacca et al. 2012), and over the course of a 34-year record in the tundra region of Alaska, there was a weakening correlation between temperature and spring carbon assimilation over the last 17 years (Piao et al. 2017). One possible explanation for the declining effect of temperature, is the lower irradiance received and shorter days earlier in the year when trees leaf-out (Stine and Huybers, 2014). Considering that spectral composition affects both the timing of bud burst and the rate of photosynthesis in plants (Sæbø et al. 1995, Matsuda et al. 2004; Hogewoning et al. 2010), and can act as a signal for the amount of light available (Casal 2013, Moriconi et al. 2018), understanding the influence of spectral composition is important if we are to assess the phenological impacts on carbon capture during spring in a warming world.

Not only can spectral composition affect the timing of leaf out and leaf senescence, but it can also affect the leaf chemistry throughout autumn and during senescence (Biswal 1995, Kotilainen et al. 2010). The increased recalcitrance of litter with high phenolic content, for instance, has cascade effects on the decomposition of the leaf litter, nutrient cycling, and the microbial community (Kotilainen et al. 2009, King et al. 2012).

\section{Tackling the problem of light pollution}

Whilst it is intriguing to consider the ecological role of spectral cues, and how plants integrate these and temperature cues, studying these processes could also be of practical importance since light pollution presents a 
666

667

668

669

670

671

672

673

674

675

676

677

678

679

680

681

682

683

684

685

686

687

688

689

690

global problem in the $21^{\text {st }}$ Century (Davies and Smyth, 2017). Artificial light has been linked with advancing the date of bud burst in several tree species across the UK (ffrench-Constant et al. 2016), and delaying leaf senescence in trees (e.g. New York, USA - Matzke et al. 1936; also photographed in Exeter, UK, - Bennie et al. 2016), and yet we still know little about how its effects on the phenology of tree species around the globe are mediated. The increased adoption of 'white' LED street lamps enriched in the blue region will expose trees to a broad spectrum of light at twilight and at night (Davies et al. 2013). If we are to tackle the issue of light pollution around the globe, we must build a comprehensive understanding of how a shift in the spectrum of street lamps can affect tree phenology.

\section{Conclusions}

To our knowledge, this is the first attempt to synthesize the effects of spectral composition on spring and autumn phenology on trees. Our findings show that the bud burst and bud set of trees growing at high latitudes exhibit a greater sensitivity to changes in R:FR than those from low latitudes, whilst there is no evidence for R:FR affecting autumnal leaf senescence. Both blue light and UV-B radiation can influence bud set in tree species, and both are candidate regions that could be affecting leaf senescence in trees. We are unaware of any studies which test the effects of green light on spring and autumn phenology. Light pollution presents a practical challenge, and exemplifies why understanding the effects of spectral composition is a priority. Focusing on photoreceptor-mediated ABA and GA hormone signalling may be a promising area of research to investigate how trees integrate multiple spectral cues to time their phenology. Improving our understanding of the spectral cues that affect the phenology of trees across multiple scales is also essential if we are to predict how temperate forest ecosystems will respond to the novel combinations of environmental cues that climate change will produce.

\section{Funding}

We thank the Finnish Academy of Science for funding this research through decisions \# 266523 and \#304519 to TM Robson and the Doctoral Programme in Plant Science for funding CC Brelsford. 
691

692

693

694

695

696

697

698

699

700

701

702

703

704

705

706

707

708

709

710

711

712

\section{Acknowledgements}

Our thanks to C Strømme for his help providing results from his studies, and RB Primack for his comments on the manuscript.

\section{References}

Anderson R, Ryser P (2015) Early autumn senescence in red maple (Acer rubrum L.) is associated with high leaf anthocyanin content. Plants 4: 505-522

Aphalo PJ (2015) The r4photobiology suite: spectral irradiance. UV4Plants Bulletin 2015: 21-29

Aphalo PJ (2016) The r4photobiology suite: sun angles and day length. UV4Plants Bulletin 2016: 29-39

Augspurger CK (2009) Spring 2007 warmth and frost: phenology, damage and refoliation in a temperate deciduous forest. Funct Ecol 23: 1031-1039

Bais AF, Lucas RM, Bornman JF, Williamson CE, Sulzberger B, Austin AT, Wilson SR, Andrady AL, Bernhard G, McKenzie RL, Aucamp PJ (2018) Environmental effects of ozone depletion, UV radiation and interactions with climate change: UNEP Environmental Effects Assessment Panel, update 2017. Photochem Photobiol Sci

Banerjee R, Batschauer A (2005) Plant blue-light receptors. Planta 220: 498-502

Banerjee R, Schleicher E, Meier S, Viana RM, Pokorny R, Ahmad M, Bittl R, Batschauer A, (2007) The signaling state of Arabidopsis cryptochrome 2 contains flavin semiquinone. J Biol Chem 282:14916-14922

Barnes PW, Flint SD, Slusser JR, Gao W, Ryel RJ (2008) Diurnal changes in epidermal UV transmittance of plants in naturally high UV environments. Physiologia Plant 133: 363-372

Barnes PW, Flint SD, Slusser JR, Gao W, Ryel RJ (2008) Diurnal changes in epidermal UV transmittance of plants in naturally high UV environments. Physiologia Plant 133: 363-372 
713 Barnes PW, Flint SD, Tobler MA, Ryel RJ (2016) Diurnal adjustment in ultraviolet sunscreen protection is $714 \quad$ widespread among higher plants. Oecologia 181: 55-63

715 Barnes PW, Ryel RJ, Flint SD (2017) UV Screening in Native and Non-native Plant Species in the Tropical 716 Alpine: Implications for Climate Change-Driven Migration of Species to Higher Elevations Front Plant Sci $717 \quad 8: 1451$

718

719

720

721

722

723

724

725

726

727

728

729

730

731

732

733

734

735

Barnola P, Crochet A, Payan E, Gendraud M, Lavarenne S (1986) Modifications of energy-metabolism and permeability in the apical bud and in stem during the temporary rest of the growth of young oak trees. Physiol veg 24:307-314

Basler D, Körner C (2012) Photoperiod sensitivity of bud burst in 14 temperate forest tree species. Ag For Met, 165: 73-81

Basler D (2016) Evaluating phenological models for the prediction of leaf-out dates in six temperate tree species across central Europe. Ag For Met, 217: 10-21

Bassman JH, Edwards GE, Robberecht R (2002) Long-term exposure to enhanced UV-B radiation is not detrimental to growth and photosynthesis in Douglas-fir. New Phytol 154: 107-120

Bennie J, Kubin E, Wiltshire A, Huntley B, Baxter R (2010) Predicting spatial and temporal patterns of bud-burst and spring frost risk in north-west Europe: the implications of local adaptation to climate. Global Change Biol 16: 1503-1514

Bennie J, Davies TW, Cruse D, Gaston KJ (2016). Ecological effects of artificial light at night on wild plants. J Ecol 104: 611-620

Biswal B (1995) Carotenoid catabolism during leaf senescence and its control by light. Journal of Photochemistry and Photobiology B: Biology 30: 3-13

Bigler C, Bugmann H (2018) Climate-induced shifts in leaf unfolding and frost risk of European trees and shrubs. Sci Rep 8: 9865 
736 Blumthaler M, Ambach W, Ellinger R (1997) Increase in solar UV radiation with altitude. J Photochem 737 Photobiol B: Biol 39: 130-134

738

739

740

741

742

743

744

745

746

747

748

749

750

751

752

753

754

755

756

757
Böhlenius H, Huang T, Charbonnel-Campaa L, Brunner AM, Jansson S, Strauss SH, Nilsson O (2006) CO/FT regulatory module controls timing of flowering and seasonal growth cessation in trees. Science 312: 10401043

Bouly JP, Schleicher E, Dionisio-Sese M, Vandenbussche F, Van Der Straeten D, Bakrim N,Meier S, Batschauer A, Galland P, Bittl R, Ahmad M (2007) Cryptochrome blue light photoreceptors are activated through interconversion of flavin redox states. J Biol Chem, 282: 9383-9391

Brelsford CC (2017) Radiative transfer theory and modelling with libRadtran. UV4Plants Bulletin, 2016: 45-50.

Brelsford CC, Robson TM (2018) Blue light advances bud burst in branches of three deciduous tree species under short-day conditions. Trees doi: (https://doi.org/10.1007/s00468-018-1684-1)

Brelsford CC, Morales LO, Nezval J, Kotilainen TK, Hartikainen SM, Aphalo PJ, Robson TM (2018). Do UV-A radiation and blue light during growth prime leaves to cope with acute high-light in photoreceptor mutants of Arabidopsis thaliana?. Physiologia plantarum.doi: (https://doi.org/10.1111/ppl.12749)

Briggs WR, Huala E (1999) Blue-light photoreceptors in higher plants Annu Rev Cell Dev Biol 15: 33-62

Briggs WR, Christie JM (2002) Phototropins 1 and 2: versatile plant blue-light receptors. Trends Plant Sci 7: 204-210

Brown BA, Cloix C, Jiang GH, Kaiserli E, Herzyk P, Kliebenstein DJ, Jenkins GI (2005) A UV-B-specific signaling component orchestrates plant UV protection. Proc Natl Acad Sci USA 102: 18225-18230

Caffarra A, Donnelly A (2011) The ecological significance of phenology in four different tree species: effects of light and temperature on bud burst. Int J Biometeorol, 55(5), 711-721

Calbó J, González JA (2005) Empirical studies of cloud effects on UV radiation: A review. Rev Geophys 43 
758 Caldwell MM, Robberecht R, Billings, WD (1980) A steep latitudinal gradient of solar ultraviolet-B radiation in 759 the arctic-alpine life zone. Ecology 61: 600-611

760 Casal JJ (2000) Phytochromes, cryptochromes, phototropin: photoreceptor interactions in plants. Photochem $761 \quad$ Photobiol 71: 1-11

762 Casal JJ (2013) Canopy light signals and crop yield in sickness and in health ISRN Agronomy

763 Catesson AM (1964) Modifications cytochimiques saisonnieres des points vegetatifs dans les bourgeons de lacer 764 pseudoplatanus. C R Acad Sci 258:5709

765 Cavender-Bares J, Potts M, Zacharias E, Bazzaz FA (2000) Consequences of CO2 and light interactions for leaf 766 phenology, growth, and senescence in Quercus rubra. Global Change Biol 6: 877-887

767 Cesaraccio C, Spano D, Snyder RL, Duce P (2004) Chilling and forcing model to predict bud-burst of crop and 768 forest species. Ag For Met 126: 1-13

769 Chambers PA, Spence DH (1984) Diurnal changes in the ratio of underwater red to far red light in relation to 770 aquatic plant photoperiodism. J Ecol 495-503

771 Chiang C, Aas OT, Jetmundsen MR, Lee Y, Torre S, Fløistad IS, Olsen JE (2018) Day Extension with Far-Red 772 Light Enhances Growth of Subalpine Fir (Abies lasiocarpa (Hooker) Nuttall) Seedlings. Forests 9: 175.

773 Chuine I, Régnière J (2017) Process-Based Models of Phenology for Plants and Animals. Annu Rev Ecol Evol $774 \quad$ Syst $48(1)$

775 Chuine I, Beaubien EG (2001) Phenology is a major determinant of tree species range. Ecol Lett, 4: 500-510

776 Clapham DH, Dormling I, Ekberg L, Eriksson G, Qamaruddin M, Vince-Prue D (1998) Latitudinal cline of 777 requirement for far-red light for the photoperiodic control of budset and extension growth in Picea abies (Norway spruce). Physiol Plant 102: 71-78 
779 Clapham, DH, Kolukisaoglu, HÜ, Larsson, CT, Qamaruddin, M, Ekberg, I, Wiegmann-Eirund, C, Schneider-

780 Poetsch, HA and von Arnold, S, 1999 Phytochrome types in Picea and Pinus Expression patterns of PHYA-

781 related types. Plant Mol Biol 40: 669-678

782 Clapham DH, Ekberg I, Eriksson G, Norell L, Vince-Prue D (2002) Requirement for far-red light to maintain

783 secondary needle extension growth in northern but not southern populations of Pinus sylvestris (Scots pine).

$784 \quad$ Physiol Plant 114: 207-212

785 Cleland EE, Chuine I, Menzel A, Mooney HA, Schwartz MD (2007) Shifting plant phenology in response to 786 global change. Trends in Ecol Evol 22: 357-365

787 Cooper HF, Grady KC, Cowan JA, Best R.J, Allan GJ. Whitham TG (2018) Genotypic variation in phenological 788 plasticity: Reciprocal common gardens reveal adaptive responses to warmer springs but not to fall frost. Glob $789 \quad$ Change Biol

790

791

Cottignies A (1986) The hydrolysis of starch as related to the interruption of dormancy in the ash bud. J Plant Physiol 123:381-388

792

Coville FV (1920) The influence of cold in stimulating the growth of plants. Proc Natl Acad Sci 6: 434-435

793

794

795

796

797

798

799

800

Davies TW, Bennie J, Inger R, de Ibarra, NH, Gaston KJ (2013). Artificial light pollution: are shifting spectral signatures changing the balance of species interactions? Global Change Biol 19: 1417-1423

Davies TW, Smyth T (2018). Why artificial light at night should be a focus for global change research in the 21st century. Global Change Biol 24: 872-882

Delpierre N, Dufrêne E, Soudani K, Ulrich E, Cecchini S, Boé J, François C (2009) Modelling interannual and spatial variability of leaf senescence for three deciduous tree species in France. Ag For Met 149: 938-948

Ding J, Nilsson O (2016) Molecular regulation of phenology in trees-because the seasons they are a-changin'. Curr Opin Plant Biol 29: 73-79 
801

802

803

804

805

806

807

808

809

810

811

812

813

814

815

816

817

818

819

820

821

822

Dotto M, Gómez MS, Soto MS, Casati P (2018) UV-B radiation delays flowering time through changes in the PRC2 complex activity and miR156 levels in Arabidopsis thaliana. Plant Cell Environ (https://doi.org/10.1111/pce.13166)

Emde, C, Buras-Schnell, R, Kylling, A, Mayer, B, Gasteiger, J, Hamann, U, Kylling, J, Richter, B, Pause, C, Dowling, T and Bugliaro, L, (2016) The libRadtran software package for radiative transfer calculations (version 20 1). Geosci Model Dev 9:1647-1672

Erez, A, Samish, R M, \& Lavee, S (1966) The role of light in leaf and flower bud break of the peach (Prunus persica). Physiol Plant 19: 650-659

Fehér B, Kozma-Bognár L, Kevei É, Hajdu A, Binkert M, Davis SJ, Schäfer E, Ulm R Nagy F (2011) Functional interaction of the circadian clock and UV RESISTANCE LOCUS 8-controlled UV-B signaling pathways in Arabidopsis thaliana. Plant J 67: 37-48

Feild TS, Lee DW, Holbrook NM (2001) Why leaves turn red in autumn The role of anthocyanins in senescing leaves of red-osier dogwood. Plant Physiol, 127: 566-574

Flynn DFB, Wolkovich EM (2018) Temperature and photoperiod drive spring phenology across all species in a temperate forest community. New Phytol (https://doi.org/10.1111/nph.15232)

Folta KM, Maruhnich SA (2007) Green light: a signal to slow down or stop. J Exp Bot 58: 3099-3111

Fracheboud Y, Luquez V, Björkén L, Sjödin A, Tuominen H, Jansson S (2009) The control of autumn senescence in European aspen. Plant Physiol 149: 1982-1991

Franklin KA, Whitelam GC (2007) Light-quality regulation of freezing tolerance in Arabidopsis thaliana. Nature Genet 39: 1410-1413

Fredericq H (1964) Conditions determining effects of far-red and red irradiations on flowering response of Pharbitis nil. Plant Physiol 39: 812 
823

824

825

826

827

828

829

830

831

832

833

834

835

836

837

838

839

840

841

842

843

844

845

Frewen BE Chen TH, Howe GT, Davis J, Rohde A, Boerjan W, Bradshaw H D (2000) Quantitative trait loci and candidate gene mapping of bud set and bud flush in Populus. Genetics 154: 837-845

Fu YH, Piao S, Vitasse Y, Zhao H, De Boeck HJ, Liu Q, Yang H, Weber U, Hänninen H, Janssens IA (2015). Increased heat requirement for leaf flushing in temperate woody species over 1980-2012: effects of chilling, precipitation and insolation. Global Change Biol 21: 2687-2697

Fuglevand G, Jackson JA, Jenkins GI (1996) UV-B, UV-A, and blue light signal transduction pathways interact synergistically to regulate chalcone synthase gene expression in Arabidopsis. Plant Cell 8: 2347-2357

ffrench-Constant R, Somers-Yeates R, Bennie J, Economou T, Hodgson D, Spalding A, McGregor PK (2016)

Light pollution is associated with earlier tree budburst across the United Kingdom. In Proc R Soc B 283: p

20160813

Gallinat AS, Primack RB, Wagner DL (2015) Autumn, the neglected season in climate change research Trends in Ecol Evol 30: 169-176

Gill AL, Gallinat AS, Sanders-DeMott R, Rigden AJ, Short Gianotti DJ, Mantooth JA, Templer PH (2015). Changes in autumn senescence in northern hemisphere deciduous trees: a meta-analysis of autumn phenology studies. Ann Bot 116: 875-888

Girault T, Bergougnoux V, Combes D, VIEMONT JD, Leduc N (2008) Light controls shoot meristem organogenic activity and leaf primordia growth during bud burst in Rosa sp Plant Cell Environ 31: 1534-1544

Girault T, Abidi F, Sigogne M, Pelleschi-Travier, Sandrine, Boumaza R, Sakr S, Leduc N (2010) Sugars are under light control during bud burst in Rosa sp. Plant Cell Environ 33: 1339-1350

Goins GD, Yorio NC, Sanwo MM, Brown CS (1997) Photomorphogenesis, photosynthesis, and seed yield of wheat plants grown under red light-emitting diodes (LEDs) with and without supplemental blue lighting $\mathrm{J}$ Exp Bot 48: 1407-1413

Goldstein BR (1976) Refraction, Twilight, and the Height of the Atmosphere. Vistas Astron 20: 105-107 
846 Guo H, Yang H, Mockler TC, Lin C (1998) Regulation of flowering time by Arabidopsis photoreceptors Science 279: 1360-1363

848

849

850

851

852

853

854

855

856

857

858

859

860

861

862

863

864

865

866

Han T, Wu C, Tong Z, Mentreddy RS, Tan K, Gai J (2006) Postflowering photoperiod regulates vegetative growth and reproductive development of soybean. Environ Exper Bot 55: 120-129

Hänninen H (1991) Does climatic warming increase the risk of frost damage in northern trees? Plant Cell Environ 14: 449-454

Hänninen H (1995) Effects of climatic change on trees from cool and temperate regions: an ecophysiological approach to modelling of bud burst phenology. Can J Bot 73: 183-199

Hayes S, Velanis CN, Jenkins GI, Franklin KA (2014) UV-B detected by the UVR8 photoreceptor antagonizes auxin signaling and plant shade avoidance. Proc Natl Acad Sci USA 111: 11894-11899

Hideg É, Jansen MA, Strid Å (2013) UV-B exposure, ROS, and stress: inseparable companions or loosely linked associates? Trends Plant Sci 18: 107-115

Hoch WA, Zeldin EL, McCown BH (2001) Physiological significance of anthocyanins during autumnal leaf senescence. Tree Physiol 21: 1-8

Hogewoning SW, Trouwborst G, Maljaars H, Poorter H, van Ieperen W, Harbinson J (2010) Blue light doseresponses of leaf photosynthesis, morphology, and chemical composition of Cucumis sativus grown under different combinations of red and blue light. J Exp Bot 61: pp3107-3117

Holmes MG, Smith H (1977) The function of phytochrome in the natural environment-II The influence of vegetation canopies on the spectral energy distribution of natural daylight. Photochem Photobiol 25: 539-545

Howe GT, Gardner G, Hackett WP, Furnier GR (1996) Phytochrome control of short-day-induced bud set in black cottonwood. Physiol Plant 97: 95-103 
867

868

869

870

871

872

873

874

875

876

877

878

879

880

881

882

883

884

885

886

887

Howe GT, Bucciaglia PA, Hackett WP, Furnier GR, Cordonnier-Pratt MM, Gardner G (1998) Evidence that the phytochrome gene family in black cottonwood has one PHYA locus and two PHYB loci but lacks members of the PHYC/F and PHYE subfamilies. Mol Biol Evol 15: 160-175

Hughes JE, Morgan DC, Lambton PA, Black CR, Smith H (1984) Photoperiodic time signals during twilight. Plant Cell Environ 7: 269-277

Hulburt EO (1953) Explanation of the brightness and color of the sky, particularly the twilight sky. JOSA 43: $113-118$

${ }^{a}$ Ibáñez I, Primack RB, Miller-Rushing AJ, Ellwood E, Higuchi H, Lee SD, Kobori H and Silander JA (2010) Forecasting phenology under global warming. Philos Trans R Soc Lond B Biol Sci 1555: 3247-3260

${ }^{b}$ Ibáñez C, Kozarewa I, Johansson M, Ögren E, Rohde A, Eriksson ME (2010) Circadian clock components regulate entry and affect exit of seasonal dormancy as well as winter hardiness in Populus trees. Plant Physiol 153: $1823-1833$

Jansen MA, Gaba V, Greenberg BM, Mattoo AK, Edelman M (1996) Low threshold levels of ultraviolet-B in a background of photosynthetically active radiation trigger rapid degradation of the D2 protein of photosystem-II Plant J 9: 693-699

Jansen MA, Bornman JF (2012) UV-B radiation: from generic stressor to specific regulator. Physiol Plant 145: $501-504$

Jenkins GI (2009) Signal transduction in responses to UV-B radiation Annu Rev Plant Biol 60:407-431

Johnsen S (2012) The optics of life: a biologist's guide to light in nature. Princeton University Press.

Johnson TB, Salisbury FB, Connor GI (1967) Ratio of blue to red light: a brief increase following sunset Science 155: $1663-1665$ 
Jones PD, Lister DH, Osborn TJ, Harpham C, Salmon M, Morice CP (2012) Hemispheric and large-scale land-surface air temperature variations: An extensive revision and an update to 2010. J Geophys Res: Atmos 117(D5).

Junttila O, Kaurin $\AA$ (1985) Climatic control of apical growth cessation in latitudinal ecotypes of Salix pentandra L. In Plant Production in the North (eds ÅKaurin, OJunttila \& JNilsen), pp 83-91 Norwegian University Press, Troms $\varnothing$

Junttila O (2007) Regulation of annual shoot growth cycle in northern tree species In Physiology of Northern Plants Under Changing Environment (eds E Taulavuori \& K Taulavori), pp 177-210 Research Signpost, Kerala, India

Kållberg P, Berrisford P, Hoskins B, Simmons A, Lamy-thépaut S, Hine R (2005) ERA-40 atlas.

Kakani VG, Reddy KR, Zhao D, Gao W (2004) Senescence and hyperspectral reflectance of cotton leaves exposed to ultraviolet-B radiation and carbon dioxide. Physiol Plant, 121(2), 250-257

Kasperbauer MJ, Borthwick HA, Hendricks SB (1963) Inhibition of flowering of Chenopodium rubrum by prolonged far-red radiation. Botanical Gazette, 124: 444-451

Kelner JJ, Lachaud S, Bonnemain JL (1993) Seasonal variations in ABA exchange between the apical bud and the underlying stem of beech Comparison with nutrients. Plant Physiol Biochem 31:523-530

King JY, Brandt LA, Adair EC (2012) Shedding light on plant litter decomposition: advances, implications and new directions in understanding the role of photodegradation. Biogeochemistry, 111: 57-81.

Klem K, Ač A, Holub P, Kováč D, Špunda V, Robson TM, Urban O (2012) Interactive effects of PAR and UV radiation on the PHYsiology, morphology and leaf optical properties of two barley varieties. Environ Exper Bot: $75,52-64$

Körner C (2007) The use of 'altitude' in ecological research Trends in Ecol Evol, 22: 569-574

Körner C, Basler D (2010) Phenology under global warming Science 327: 1461-1462 
911 Kotilainen T, Venäläinen T, Tegelberg R, Lindfors A, Julkunen-Tiitto R, Sutinen, Sutinen S, O’Hara RB \& 912 Aphalo PJ (2009) Assessment of UV biological spectral weighting functions for phenolic metabolites and 913 growth responses in silver birch seedlings. Photochemistry and photobiology 85: 1346-1355

914 Kotilainen T, Tegelberg R, Julkunen-Tiitto R, Lindfors A, O'Hara RB, Aphalo PJ (2010) Seasonal fluctuations 915 in leaf phenolic composition under UV manipulations reflect contrasting strategies of alder and birch trees. $916 \quad$ Physiologia plantarum 140: 297-309

917 Košvancová-Zitová M, Urban O, Navrátil M, Špunda V, Robson TM, Marek MV (2009) Blue radiation 918 stimulates photosynthetic induction in Fagus sylvatica L. Photosynthetica 47: 388

919 Kozarewa I, Ibáñez C, Johansson M, Ögren E, Mozley D, Nylander E, Chono M, Moritz T, Eriksson ME, (2010) 920 Alteration of PHYA expression change circadian rhythms and timing of bud set in Populus. Plant Mol Biol $921 \quad 73(1-2)$, pp143-156

922 Kramer K (1994) A modelling analysis of the effects of climatic warming on the probability of spring frost 923 damage to tree species in The Netherlands and Germany. Plant Cell Environ 17: 367-377

924 Kriebel HB (1957) Patterns of genetic variation in sugar maple. Bul Ohio Agr Exp Sta 791: 3-56

925 Kubasek WL, Shirley BW, McKillop A, Goodman HM, Briggs W, Ausubel FM (1992) Regulation of flavonoid 926 biosynthetic genes in germinating Arabidopsis seedlings. Plant Cell 4: 1229-1236

927 Kvifte G, Hegg K, Hansen V (1983) Spectral distribution of solar radiation in the Nordic countries. J Appl 928 Meteorol Climatol, 22: 143-152

929 Lagercrantz U (2009) At the end of the day: a common molecular mechanism for photoperiod responses in 930 plants? J Exp Bot 60: 2501-2515

931 Lane HC, Cathey HM, Evans LT (1965) The dependence of flowering in several long-day plants on the spectral 932 composition of light extending the photoperiod. Am J Bot 52: 1006-1014 
933 934

Lang GA (1987) Endo-, para-, and ecodormancy: Physiological terminology and classification for dormancy research. HortSci 22:371-377

Lee DW, O'keefe J, Holbrook NM, Feild TS (2003) Pigment dynamics and autumn leaf senescence in a New England deciduous forest, eastern USA. Ecol Res 18: 677-694

Lee DW, Downum KR (1991) The spectral distribution of biologically active solar radiation at Miami, Florida, USA. Int J Biometeorol 35: 48-54

Leinonen I, Kramer K (2002) Applications of phenological models to predict the future carbon sequestration potential of boreal forests. Clim Change 55: 99-113

Li C, Junttila O, Ernstsen A, Heino P, Palva ET (2003) Photoperiodic control of growth, cold acclimation and dormancy development in silver birch (Betula pendula) ecotypes Physiol Plant 117: 206-212

Li X, Ma M, Shao W, Wang H, Fan R, Chen X, Wang X, Zhan Y, Zeng F (2018). Molecular cloning and functional analysis of a UV-B photoreceptor gene, BpUVR8 (UV Resistance Locus 8), from birch and its role in ABA response. Plant Sci 274: 294-308

Liu Q, Fu YH, Zeng Z, Huang M, Li X, Piao S (2016). Temperature, precipitation, and insolation effects on autumn vegetation phenology in temperate China. Global Change Biol 22: 644-655

Lin C (2000) Plant blue-light receptors. Trends Plant Sci 5: 337-342

Lin C, Ahmad M, Cashmore AR (1996) Arabidopsis cryptochrome 1 is a soluble protein mediating blue light-dependent regulation of plant growth and development. Plant J 10: 893-902

Linkosalo T, Lechowicz MJ (2006) Twilight far-red treatment advances leaf bud burst of silver birch (Betula pendula). Tree Physiol 26: 1249-1256

Litthauer S, Battle MW, Lawson T, Jones MA (2015) Phototropins maintain robust circadian oscillation of PSII operating efficiency under blue light. Plant J 83: 1034-1045 
955

956

957

958

959

960

961

962

963

964

965

966

967

968

969

970

971

972

973

974

975

976

977
López-Figueroa F (1992) Diurnal variation in pigment content in Porphyra laciniata and Chondrus crispus and its relation to the diurnal changes of underwater light quality and quantity. Mar Ecol 13: 285-305

Lüttge U, Hertel B (2009) Diurnal and annual rhythms in trees. Trees 23: 683

Manney GL, Lawrence ZD (2016) The major stratospheric final warming in 2016: dispersal of vortex air and termination of Arctic chemical ozone loss. Atmos Chem Phys 16: 15371-15396

Mao J, Zhang YC, Sang Y, Li QH, Yang HQ (2005) A role for Arabidopsis cryptochromes and COP1 in the regulation of stomatal opening. Proc Natl Acad Sci USA, 102: 12270-12275

Martínez C, Pons E, Prats G, León J (2004) Salicylic acid regulates flowering time and links defence responses and reproductive development Plant J 37: 209-217

Matsuda R, Ohashi-Kaneko K, Fujiwara K, Goto E, Kurata K (2004) Photosynthetic characteristics of rice leaves grown under red light with or without supplemental blue light. Plant Cell Physiol 45: 1870-1874

Materová Z, Sobotka R, Zdvihalová B, Oravec M, Nezval J, Karlický V, Vrábl D, Štroch M, Špunda V (2017) Monochromatic green light induces an aberrant accumulation of geranylgeranyled chlorophylls in plants. Plant Physiol and Biochem 116: 48-56

Maurya JP, Bhalerao RP (2017) Photoperiod-and temperature-mediated control of growth cessation and dormancy in trees: a molecular perspective. Ann Bot

Matzke EB (1936) The effect of street lights in delaying leaf-fall in certain trees. Am J Bot: 446-452

${ }^{a}$ McKenzie RL, Johnston PV, Smale D, Bodhaine BA, Madronich, S (2001) Altitude effects on UV spectral irradiance deduced from measurements at Lauder, New Zealand, and at Mauna Loa Observatory, Hawaii J Geophys Res, 106: 22845-22860

${ }^{b}$ McKenzie RL, Seckmeyer G, Bais AF, Kerr JB, Madronich S (2001) Satellite retrievals of erythemal UV dose compared with ground-based measurements at northern and southern midlatitudes J Geophys Res, 106: $24051-24062$ 
978

979

980

981

982

983

984

985

986

987

988

989

990

991

992

993

994

995

996

997

998

999

1000

McKenzie RL, Aucamp PJ, Bais AF, Björn LO, Ilyas M, Madronich S (2011) Ozone depletion and climate change: impacts on UV radiation. Photochem Photobiol Sci, 10: 182-198

Mercado LM, Bellouin N, Sitch S, Boucher O, Huntingford C, Wild M, Cox PM (2009) Impact of changes in diffuse radiation on the global land carbon sink. Nature 458: 1014-1017

Meng Y, Li H, Wang Q, Liu B, Lin C (2013) Blue light-dependent interaction between cryptochrome2 and CIB1 regulates transcription and leaf senescence in soybean Plant Cell 25: 4405-4420

Menzel A, Sparks TH, Estrella N, Koch E, Aasa A, Ahas R, Alm Kübler K, Bissoll, P, Braslavská OG, Briede A Chmielewski FM, (2006) European phenological response to climate change matches the warming pattern Global Change Biol 12: 1969-1976

Michelson IH, Ingvarsson PK, Robinson KM., Edlund E, Eriksson ME, Nilsson O, Jansson S (2018) Autumn senescence in aspen is not triggered by day length. Physiol Plant 162: 123-134

Migliavacca M, Sonnentag O, Keenan TF, Cescatti A, O'keefe J, Richardson AD (2012) On the uncertainty of phenological responses to climate change, and implications for a terrestrial biosphere model. Biogeosciences 9: 2063-2083.

Mockler T, Yang H, Yu X, Parikh D, Cheng YC, Dolan S, Lin C (2003) Regulation of photoperiodic flowering by Arabidopsis photoreceptors. Proc Natl Acad Sci USA, 100: 2140-2145

Mølmann JA, Junttila O, Johnsen $\varnothing$ and Olsen JE (2006) Effects of red, far-red and blue light in maintaining growth in latitudinal populations of Norway spruce (Picea abies) Plant Cell Environ 29: 166-172

Morales LO, Brosché M, Vainonen J, Jenkins GI, Wargent JJ, Sipari N, Strid Å, Lindfors AV, Tegelberg R, Aphalo PJ (2013) Multiple roles for UV RESISTANCE LOCUS8 in regulating gene expression and metabolite accumulation in Arabidopsis under solar ultraviolet radiation. Plant Physiol 161: 744-759

Morgan DC, Smith H (1981) Non-photosynthetic responses to light quality In Physiological Plant Ecology I (pp 109-134) Springer Berlin Heidelberg 
1001 Moriconi V, Binkert M, Rojas MCC, Sellaro R, Ulm R, Casal JJ (2018) Perception of sunflecks by the UV-B 1002 photoreceptor UV RESISTANCE LOCUS 8. Plant Physiol 00048 (https://doi.org/10.1104/pp.18.00048)

1003 Murchie EH, Horton P (1998) Contrasting patterns of photosynthetic acclimation to the light environment are 1004 dependent on the differential expression of the responses to altered irradiance and spectral quality. Plant Cell $1005 \quad$ Environ 21: 139-148

1006

1007

1008

1009

1010

1011

1012

1013

1014

1015

1016

1017

1018

1019

1020

1021

1022

Muleo R, Morini S, Casano S (2001) Photoregulation of growth and branching of plum shoots: Physiological action of two photosystems. In Vitro Cell Dev Biol 37: 609-617

Myking T, Heide OM (1995) Dormancy release and chilling requirement of buds of latitudinal ecotypes of Betula pendula and B. pubescens. Tree Physiol 15: 697-704

Myneni RB, Keeling CD, Tucker CJ, Asrar G, Nemani RR (1997) Increased plant growth in the northern high latitudes from 1981 to 1991. Nature 386: 698.

Nilsen J (1985) Light climate in northern areas In Plant production in the North: proceedings from Plant Adaptation Workshop, Tromso, Norway, September 4-9, 1983/edited by Ase Kaurin, Olavi Juntilla and Jarle Nilsen Tromso: Norwegian University Press, c1985

Nishio JN (2000) Why are higher plants green? Evolution of the higher plant photosynthetic pigment complement. Plant Cell Environ 23: 539-548

Oakenfull RJ, Davis SJ (2017) Shining a light on the Arabidopsis circadian clock. Plant, cell \& environment, 40: 2571-2585

Ohgishi M, Saji K, Okada K, Sakai T (2004) Functional analysis of each blue light receptor, cry1, cry2, phot1, and phot2, by using combinatorial multiple mutants in Arabidopsis. Proc Natl Acad Sci USA 101: 2223-2228

Okie WR, Blackburn B (2011) Interactive effects of light and chilling on peach flower and leaf budbreak HortSci, 46: 1056-1062 
$1023{ }^{a}$ Olsen JE, Moritz T, Jensen E, Junttila O (1995) Lack of effect of photoperiod on metabolism of exogenous 1024 GA19 and GA1 in Salix pentandra seedlings. Physiol Plant 94: 522-528

$1025{ }^{\mathrm{b}}$ Olsen JE, Junttila O, Moritz T (1995) A localised decrease of GA1 in shoot tips of Salix pentandra seedings 1026 precedes cessation of shoot elongation under short photoperiod. Physiol Plant 95: 627-632

$1027{ }^{a}$ Olsen JE, Junttila O, Moritz T (1997) Long-day induced bud break in Salix pentandra is associated with 1028 transiently elevated levels of GA1 and gradual increase in indole-3-acetic acid. Plant Cell Physiol 38: 536$1029 \quad 540$

${ }^{\mathrm{b}}$ Olsen JE,Junttila O (1997) Growth-promoting activity of gibberellins on shoot elongation in Salix pentandra is 1031 reduced by 16, 17-dihydro derivatisation. Physiol Plant 99: 63-66

1032 Olsen JE, Junttila O (2002) Far red end-of-day treatment restores wild type-like plant length in hybrid aspen 1033 overexpressing phytochrome A. Physiol Plant 115: 448-457

1034 Olsen JE (2010) Light and temperature sensing and signaling in induction of bud dormancy in woody plants $1035 \quad$ Plant Mol Biol 73: 37-47

1036 Olson MS, Levsen N, Soolanayakanahally RY, Guy RD, Schroeder RW, Keller SR, Tiffin P (2013) The 1037 adaptive potential of Populus balsamifera L. to phenology requirements in a warmer global climate. Mol Ecol $1038 \quad 22: 1214-1230$

Olsson C, Jönsson AM (2014) Process-based models not always better than empirical models for simulating budburst of Norway spruce and birch in Europe. Global Change Biol 20: 3492-3507

1041 Opseth L, Holefors A, Rosnes AKR, Lee Y, Olsen JE (2016) FTL2 expression preceding bud set corresponds 1042 with timing of bud set in Norway spruce under different light quality treatments. Environ Exper Bot 121: 121-131 
1044 Osada N, Murase K, Tsuji K, Sawada H, Nunokawa K, Tsukahara M, Hiura T (2018) Genetic differentiation in 1045 the timing of budburst in Fagus crenata in relation to temperature and photoperiod. Int J Biometeorol 62: $1046 \quad 1763-1776$

1047 Panchen ZA, Primack RB, Gallinat AS, Nordt B, Stevens AD, Du Y, Fahey R (2015) Substantial variation in 1048 leaf senescence times among 1360 temperate woody plant species: implications for phenology and ecosystem $1049 \quad$ processes Ann Bot 116: 865-873

1050 Piao S, Liu Z, Wang T, Peng S, Ciais P, Huang M, Ahlstrom A, Burkhart JF, Chevallier F, Janssens I.A and 1051 Jeong SJ (2017) Weakening temperature control on the interannual variations of spring carbon uptake across 1052 northern lands. Nature Climate Change 7: 359

1053 Post E, Steinman BA, Mann ME (2018) Acceleration of phenological advance and warming with latitude over 1054 the past century. Sci Rep 8: 3927

1055

1056

Pudasaini, A, Zoltowski BD (2013) Zeitlupe senses blue-light fluence to mediate circadian timing in Arabidopsis thaliana. Biochem 52: 7150-7158

Ragni M, Ribera D'Alcalà M (2004) Light as an information carrier underwater. J Plankton Res 26: 433-443

Richardson AD, Keenan TF, Migliavacca M, Ryu Y, Sonnentag O, Toomey M (2013) Climate change, phenology, and phenological control of vegetation feedbacks to the climate system. Ag For Met 169: 156-173

Richardson AD, Hufkens K, Milliman T, Aubrecht DM, Furze ME, Seyednasrollah B, Krassovski MB, Latimer JM, Nettles WR, Heiderman RR, Warren JM (2018). Ecosystem warming extends vegetation activity but heightens vulnerability to cold temperatures. Nature 560: 368-371

Rinne P, Saarelainen A, Junttila O (1994) Growth cessation and bud dormancy in relation to ABA level in seedlings and coppice shoots of Betula pubescens as affected by a short photoperiod, water stress and chilling. Physiol Plant 90:451-458 
1066

1067

1068

1069

1070

1071

1072

1073

1074

1075

1076

1077

1078

1079

1080

1081

1082

1083

1084

1085

1086

1087

1088

Rizzini L, Favory JJ, Cloix C, Faggionato D, O’Hara A, Kaiserli E, Baumeister R, Schäfer E, Nagy F, Jenkins, GI, Ulm R (2011) Perception of UV-B by the Arabidopsis UVR8 protein. Science 332: 103-106

Rohde A, Bastien C, Boerjan W (2011) Temperature signals contribute to the timing of photoperiodic growth cessation and bud set in poplar. Tree Physiol 31: 472-482

Robertson G (1966) The light composition of solar and sky spectra available to plants. Ecology 47: 640-643

Robson TM, Aphalo PJ (2012) Species-specific effect of UV-B radiation on the temporal pattern of leaf growth. Physiol Plant 144, 146-160.

Robson TM, Rasztovits E, Aphalo PJ, Alia R, Aranda I (2013) Flushing phenology and fitness of European beech (Fagus sylvatica L.) provenances from a trial in La Rioja, Spain, segregate according to their climate of origin. Ag For Met 180 76-85

Rozema J, van de Staaij J, Björn LO, Caldwell M (1997) UV-B as an environmental factor in plant life: stress and regulation. Trends Ecol Evol 12: 22-28

Ruttink T, Arend M, Morreel K, Storme V, Rombauts S, Fromm J, Bhalerao RP, Boerjan W and Rohde A, (2007) A molecular timetable for apical bud formation and dormancy induction in poplar. Plant Cell 19: 2370-2390

Sæbø A, Krekling T, Appelgren M (1995) Light quality affects photosynthesis and leaf anatomy of birch plantlets in vitro. PCTOC 41: 177-185.

Sarala M, Tahkokorpi M, Niinimaa A, Laine K, Taulavuori E, Taulavuori K (2013) Street lamp light does not delay autumnal leaf colouration of Betula pendula. Trees 27: 1193-1199

Schaber J, Badeck FW (2003) Physiology-based phenology models for forest tree species in Germany. Inter J Biometeorol 47: 193-201

Sellaro R, Crepy M, Trupkin SA, Karayekov E, Buchovsky AS, Rossi C, Casal JJ (2010) Cryptochrome as a sensor of the blue/green ratio of natural radiation in Arabidopsis. Plant Physiol, 154: 401-409 
1089

1090

1091

1092

1093

1094

1095

1096

1097

1098

1099

1100

1101

1102

1103

1104

1105

1106

1107

1108

1109

1110
Shalitin D, Yang H, Mockler TC, Maymon M, Guo H, Whitelam GC, Lin C (2002) Regulation of Arabidopsis cryptochrome 2 by blue-light-dependent phosphorylation. Nature 417: 763-767

Siipola SM, Kotilainen T, Sipari N, Morales LO, Lindfors AV, Robson T, Aphalo, PJ (2015) Epidermal UV-A absorbance and whole-leaf flavonoid composition in pea respond more to solar blue light than to solar UV radiation. Plant Cell Environ 38: 941-952

Singh RK, Svystun T, AlDahmash B, Jönsson AM, Bhalerao RP (2017) Photoperiod-and temperature-mediated control of phenology in trees-a molecular perspective. New Phytol 213: 511-524

Sivadasan U, Randriamanana TR, Julkunen-Tiitto R, Nybakken L (2015) The vegetative buds of Salix myrsinifolia are responsive to elevated UV-B and temperature. Plant Physiol and Biochemistry 93: 66-73

Sivadasan U, Randriamanana T, Chenhao C, Virjamo V, Nybakken L, Julkunen-Tiitto R (2017) Effect of climate change on bud phenology of young aspen plants (Populus tremula L). Ecol Evo 7: 7998-8007

Stine AR, Huybers P (2014) Arctic tree rings as recorders of variations in light availability. Nature communications 5: 3836 .

Smith, H (1982) Light quality, photoperception, and plant strategy Annu Rev Plant Physiol , 33(1), 481-518

Smith H, Morgan DC (1983) The function of phytochrome in nature In Photomorphogenesis (pp 491-517) Springer Berlin Heidelberg

Smith HL, McAusland L, Murchie EH (2017) Don't ignore the green light: exploring diverse roles in plant processes. J Exp Bot 68: 2099-2110

Somers DE, Devlin PF, Kay SA (1998) Phytochromes and cryptochromes in the entrainment of the Arabidopsis circadian clock. Science 282: 1488-1490

Song YH, Ito S, Imaizumi T (2013) Flowering time regulation: photoperiod-and temperature-sensing in leaves. Trends Plant Sci, 18: 575-583 
1111 Soriano G, Cloix C, Heilmann M, Núñez-Olivera E, Martínez-Abaigar J, Jenkins GI (2018) Evolutionary

1112 conservation of structure and function of the UVR8 photoreceptor from the liverwort Marchantia polymorpha 1113 and the moss physcomitrella patens. New Phytol 217: 151-162

1114 Strømme CB, Julkunen-Titto R, Krishna U, Lavola A, Olsen JE, Nybakken L (2015) UV-B and temperature 1115 enhancement affect spring and autumn phenology in Populus tremula. Plant Cell Environ 38: 867-877

$1116{ }^{a}$ Strømme CB, Sivadasan U, Nissinen K, Lavola A, Randriamanana T, Julkunen-Tiitto R, Nybakken L (2018)

1117 Interannual variation in UV-B and temperature effects on bud phenology and growth in Populus tremula. 1118 Plant Physiol Biochem

$1119{ }^{\mathrm{b}}$ Strømme CB, Julkunen-Tiitto R, Olsen JE, Nybakken L (2018) The dioecious Populus tremula displays 1120 interactive effects of temperature and ultraviolet-B along a natural gradient. Environ Exper Bot 146: 13-26

1121 Stinchcombe JR, Weinig C, Ungerer M, Olsen KM, Mays C, Halldorsdottir SS, Purugganan MD, Schmitt J 1122 (2004) A latitudinal cline in flowering time in Arabidopsis thaliana modulated by the flowering time gene $1123 \quad$ FRIGIDA Proc Natl Acad Sci USA 101: 4712-4717

1124 Sun J, Nishio JN, Vogelmann TC (1998) Green light drives CO2 fixation deep within leaves Plant Cell Physiol, 1125 39: 1020-1026

1126 Taulavuori K, Sarala M, Taulavuori E (2010) Growth responses of trees to Arctic light environment In Progress 1127 in Botany 71 (pp 157-168) Springer Berlin Heidelberg

1128 Thum KE, Kim M, Christopher DA, Mullet JE (2001) Cryptochrome 1, cryptochrome 2, and phytochrome A co1129 activate the chloroplast psbD blue light-responsive promoter. Plant Cell 13: 2747-2760

1130 Tsegay BA, Lund L, Nilsen J, Olsen JE, Mølmann JM, Ernsten A, Juntttila O (2005) Growth responses of Betula 1131 pendula ecotypes to red and far-red light. Electron J Biotechnol 8: 17-23 
1132 Tuskan GA, Difazio S, Jansson S, Bohlmann J, Grigoriev I, Hellsten U, Putnam N, Ralph S, Rombauts S, 1133 Salamov A and Schein J, (2006) The genome of black cottonwood, Populus trichocarpa (Torr \& Gray) $1134 \quad$ Science, 313: 1596-1604

1135 Urban O, JANOUŠ D, Acosta M, CZERNÝ R, Markova I, NavrATil M, Pavelka M, POKORNÝ R, ŠPRTOVÁ 1136 M, Zhang R and ŠPUNDA V (2007) Ecophysiological controls over the net ecosystem exchange of mountain 1137 spruce stand Comparison of the response in direct vs diffuse solar radiation. Global Change Biol 13: 157-168

1138 Valverde F, Mouradov A, Soppe W, Ravenscroft D, Samach A, Coupland G (2004) Photoreceptor regulation of 1139 CONSTANS protein in photoperiodic flowering. Science 303: 1003-1006

1140 Vaartaja O (1959) Evidence of photoperiodic ecotypes in trees. Ecol Monogr 29: 91-111

1141 Verdaguer D, Jansen MA, Llorens L, Morales LO, Neugart S (2016) UV-A radiation effects on higher plants: 1142 Exploring the known unknown. Plant Sci

1143 Vitasse Y, François C, Delpierre N, Dufrêne E, Kremer A, Chuine I, Delzon S (2011) Assessing the effects of 1144 climate change on the phenology of European temperate trees. Ag For Met 151: 969-980

1145 Way DA (2011) Tree phenology responses to warming: spring forward, fall back?. Tree physiol 31: 469-471

1146 Way DA, Montgomery RA (2015) Photoperiod constraints on tree phenology, performance and migration in a $1147 \quad$ warming world. Plant Cell Environ 38: 1725-1736

1148 Wade HK, Bibikova TN, Valentine WJ, Jenkins GI (2001) Interactions within a network of phytochrome, 1149 cryptochrome and UV-B phototransduction pathways regulate chalcone synthase gene expression in 1150 Arabidopsis leaf tissue. Plant J 25: 675-685

1151 Welling A, Palva ET (2006) Molecular control of cold acclimation in trees. Physiol Plant 127: 167-181

1152 Whitelam GC, Devlin PF (1997) Roles of different phytochromes in Arabidopsis photomorphogenesis Plant Cell $1153 \quad$ Environ 20: 752-758 
1154 Wild M (2009) Global dimming and brightening: A review. J Geophys Res, 114

1155 Xu X, Zhao H, Zhang X, Hänninen H, Korpelainen H, Li C (2010) Different growth sensitivity to enhanced UV-

1156 B radiation between male and female Populus cathayana. Tree Physiol 30: 1489-1498

1157 Zhang Q, Li H, Li R, Hu R, Fan C, Chen F, Wang Z, Liu X, Fu Y, Lin C (2008) Association of the circadian

1158 rhythmic expression of GmCRY1a with a latitudinal cline in photoperiodic flowering of soybean. Proc Natl

$1159 \quad$ Acad Sci USA 105: 21028-21033

1160 Zeuthen J, Mikkelsen TN, Paludan-Müller G, Ro-Poulsen H (1997). Effects of increased UV-B radiation and

1161 elevated levels of tropospheric ozone on Physiological processes in European beech (Fagus sylvatica).

1162 Physiologia Plant 100: 281-290

1163

1164

1165

1166

1167

1168

1169

1170

1171

1172

1173 
1174 Table 1: Breakdown of studies investigating the effects of spectral composition on bud burst. Studies are

1175 separated according to the regions of solar radiation they considered, either R/FR, blue light, or UV radiation. To

1176 allow a comparison of the different irradiances used in different studies, we give both the original units from

1177 each study and an estimate of irradiance following conversion to standard units of energy irradiance in $\mathrm{W} \mathrm{m} \mathrm{m}^{-2}$

1178 based on the spectra provided in the studies, and using the photobiology package in R (Aphalo, Pedro J., ed.,

1179 2013-2018, www.r4photobiology.info ISSN 2343-3248, Helsinki; Aphalo 2015).

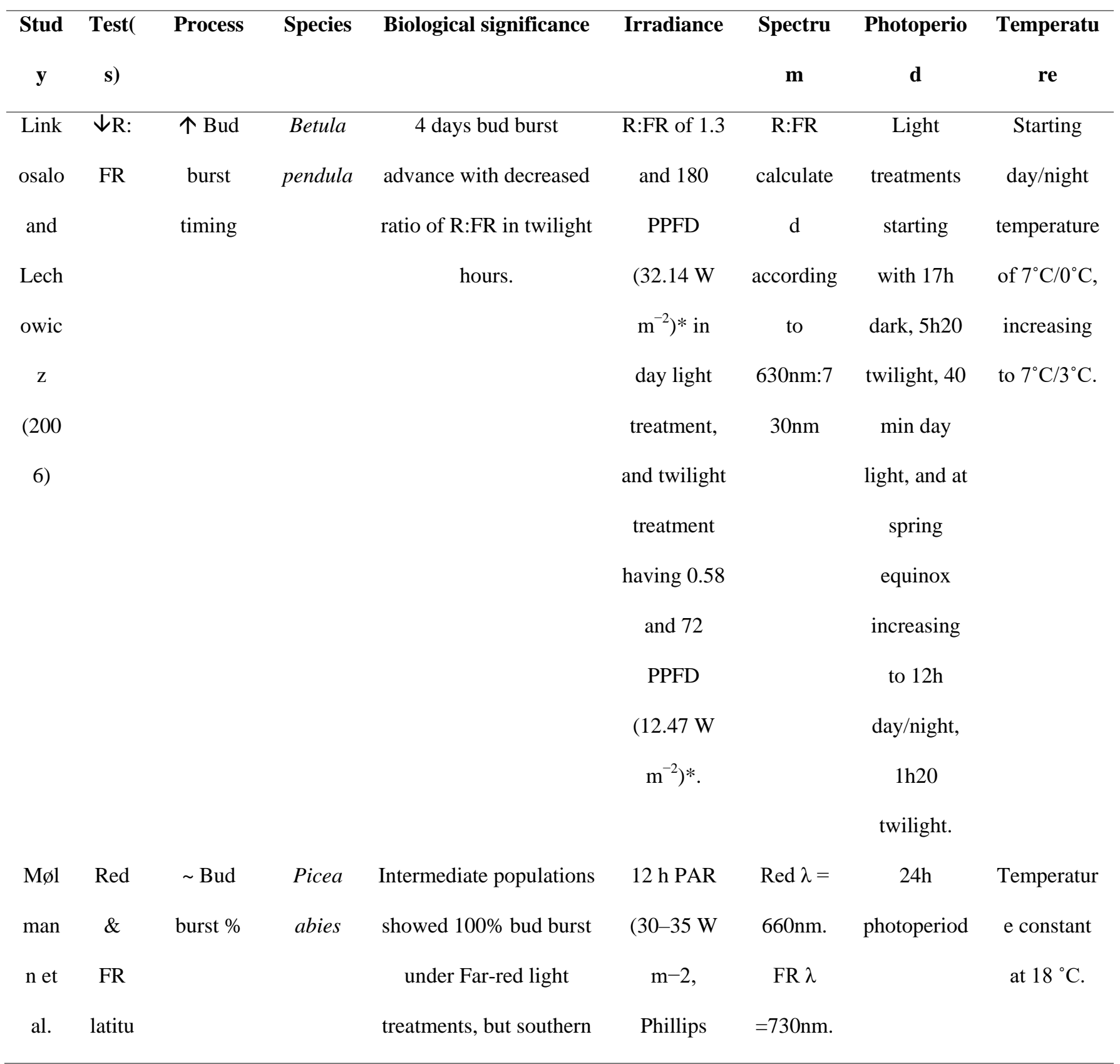




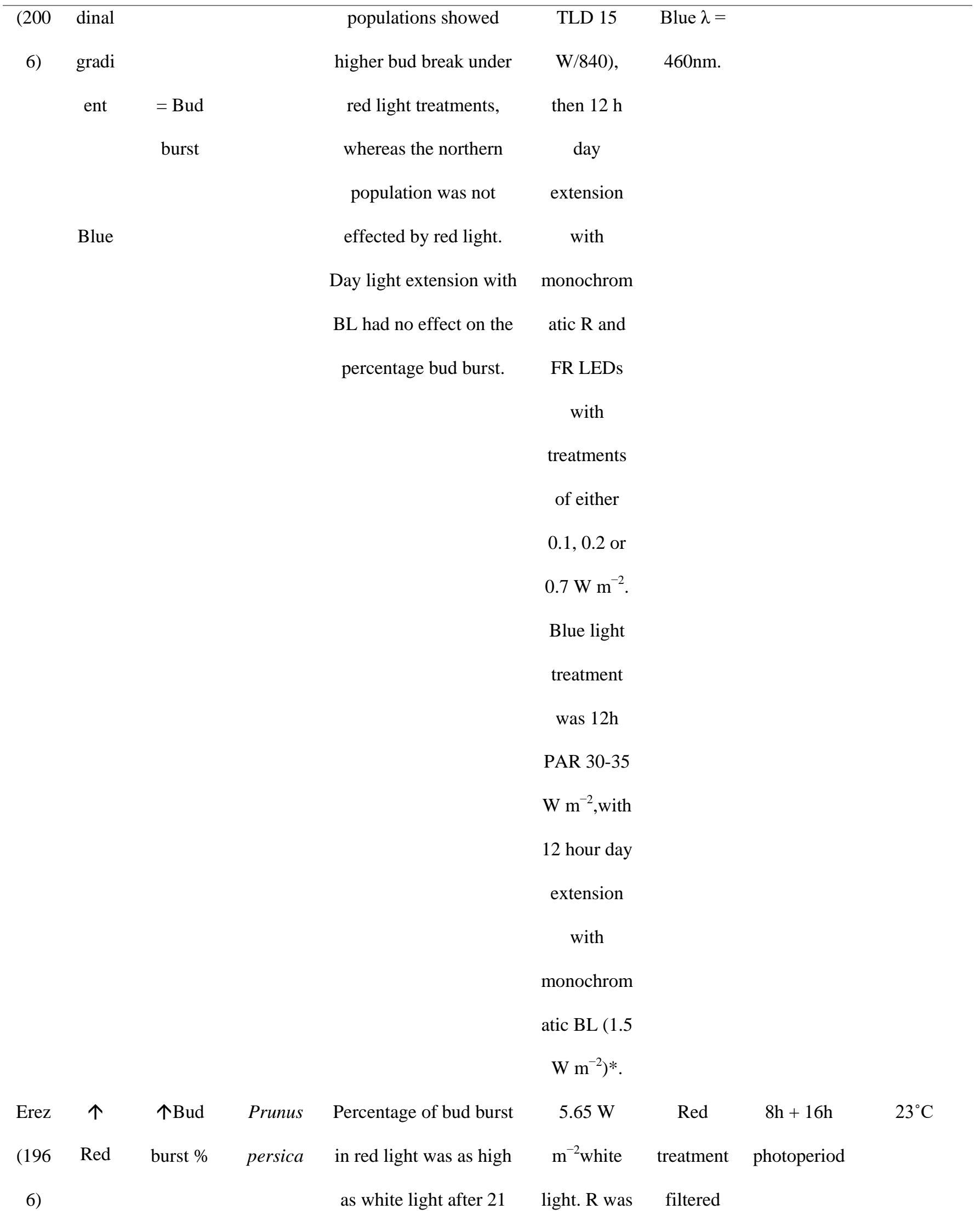




\begin{tabular}{|c|c|c|c|c|c|c|c|c|}
\hline & $\uparrow$ & $=\mathrm{Bud}$ & & days. Bud burst did not & $1.35 \mathrm{~W}$ & out any & & \\
\hline & FR & burst $\%$ & & occur without light. & $\mathrm{m}-2$. & light & & \\
\hline & & & & Flowering did occur & & below & & \\
\hline & & & & without light. FR light & & $590 \mathrm{~nm}$ & & \\
\hline & & & & did not increase $\%$ bud & & on a & & \\
\hline & & & & burst. & & broad & & \\
\hline & & & & & & spectrum & & \\
\hline & & & & & & white & & \\
\hline & & & & & & lamp & & \\
\hline & & & & & & $(400-$ & & \\
\hline & & & & & & 800nm). & & \\
\hline Brels & $\uparrow$ & 个Bud & Alnus & Broad spectrum enriched & 159 PPFD & Broad & $12 \mathrm{~h}$ & $12.6 / 9.5 \pm$ \\
\hline ford & Blue & burst & glutinos & with blue light advanced & PAR $(30$ & spectrum & photoperiod & $0.05^{\circ} \mathrm{C}$ \\
\hline and & & timing & $a$ & bud burst by 3.3 days in & $\left.\mathrm{m}^{-2}\right)-$ & LED & & Day/Night. \\
\hline Robs & & & Betula & B. pendula, 6 days in $A$. & & Lamp & & \\
\hline on & & & Pendul & glutinosa, and 6.3 days & & containin & & \\
\hline$(201$ & & & $a$ & in $Q$. robur. & & g FR & & \\
\hline \multirow[t]{10}{*}{ 8) } & & & Quercu & & & light. & & \\
\hline & & & s robur & & & Blue $=$ & & \\
\hline & & & & & & $400-$ & & \\
\hline & & & & & & $500 \mathrm{~nm}$. & & \\
\hline & & & & & & Red $=$ & & \\
\hline & & & & & & $620-$ & & \\
\hline & & & & & & $680 \mathrm{~nm}$ & & \\
\hline & & & & & & $\mathrm{FR}=$ & & \\
\hline & & & & & & $725-$ & & \\
\hline & & & & & & $735 \mathrm{~nm}$ & & \\
\hline
\end{tabular}




\begin{tabular}{|c|c|c|c|c|c|c|c|c|}
\hline Gira & $\uparrow B 1$ & 个 Bud & Rosa & Measuring the bud burst & White light & $\operatorname{Red} \lambda=$ & $16 \mathrm{~h}$ & $23^{\circ} \mathrm{C}$ \\
\hline ult et & ue & burst $\%$ & sp. & for axillary shoots. A & at $2,20,200$ & $660 \mathrm{~nm}$ & photoperiod & \\
\hline al. & & & & higher percentage of & PPFD $(0.4$, & $\operatorname{FR} \lambda=$ & & \\
\hline$(200$ & & & & grafted rose plants had & $4,400 \mathrm{~W}$ & $710 \mathrm{~nm}$ & & \\
\hline \multirow[t]{17}{*}{ 8) } & & & & burst their buds after & $\left.\mathrm{m}^{-2}\right)^{*}, \mathrm{BL}$ & Blue $\lambda=$ & & \\
\hline & $\uparrow \operatorname{Re}$ & $\downarrow$ Bud & Rosa & 12 days in white and blue & at 200 & $450 \mathrm{~nm}$ & & \\
\hline & $\mathrm{d}$ & burst $\%$ & sp. & light. & PPFD & & & \\
\hline & & & & & $(53.168 \mathrm{~W}$ & $\mathrm{R} / \mathrm{FR}$ & & \\
\hline & & & & Red light was less & $\left.\mathrm{m}^{-2}\right)^{*}, \mathrm{R}$ at & ratios & & \\
\hline & & & & efficient than white light & 20 PPFD & were the & & \\
\hline & & & & in terms of the & $(3.625 \mathrm{~W}$ & following & & \\
\hline & & & & percentage of plants & $\left.\mathrm{m}^{-2}\right)^{*}$ & : (1) 4.39 & & \\
\hline & & & & reaching bud burst after & & for white & & \\
\hline & & & & 12 days, however the red & & light; (2) & & \\
\hline & & & & light vs blue light were & & 0.78 for & & \\
\hline & & & & not compared at the & & blue & & \\
\hline & & & & same energy irradiance. & & light; (3) & & \\
\hline & & & & & & 20.27 for & & \\
\hline & & & & & & red; and & & \\
\hline & & & & & & (4) 0.25 & & \\
\hline & & & & & & for FR. & & \\
\hline Okie & $\uparrow B 1$ & $\uparrow$ Bud & Prunus & After 27 days, bud burst & B: 18.9 & Blue $\lambda=$ & $12 \mathrm{~h}$ & $18.3{ }^{\circ} \mathrm{C}$ \\
\hline and & ue & burst $\%$ & persica & in the twigs of P.persica & PPFD (4.76 & $475 \mathrm{~nm}$ & photoperiod & \\
\hline Blac & & $\uparrow$ Bud & & had a higher percentage & $\left(\mathrm{W} \mathrm{m}^{-2}\right)^{*}$ & Yellow $\lambda$ & & \\
\hline kbur & & burst & & and faster development & Yellow: & $=590 \mathrm{~nm}$ & & \\
\hline $\mathrm{n}$ & & timing & & under Red LED's, & 21.2 PPFD & $\operatorname{Red} \lambda=$ & & \\
\hline$(201$ & $\uparrow Y e$ & & & followed by Yellow then & $(4.298 \mathrm{~W}$ & $640 \mathrm{~nm}$ & & \\
\hline 1) & llow & 个>Blue & & Blue. However, this & $\left.\mathrm{m}^{-2}\right)^{*}$ & & & \\
\hline
\end{tabular}




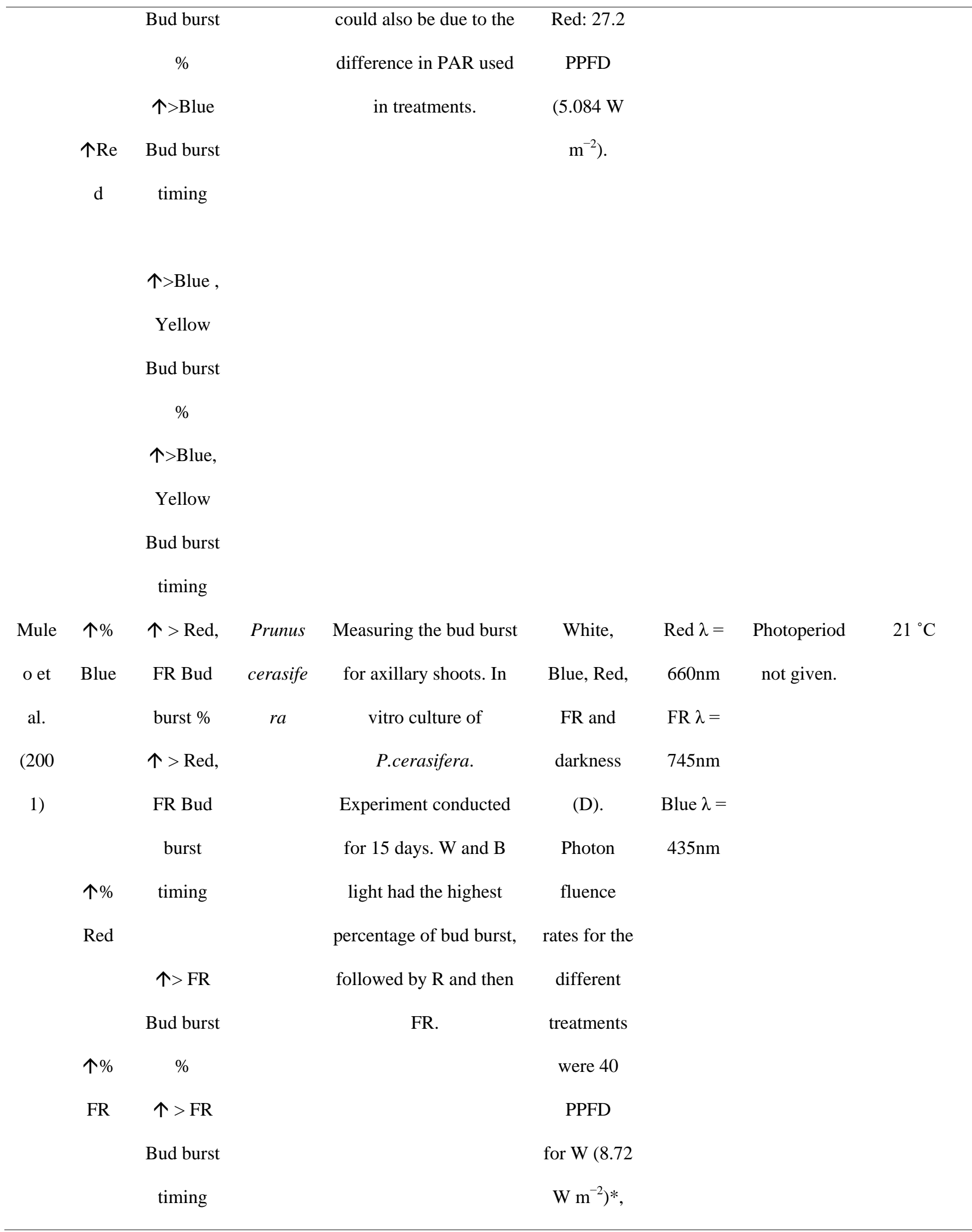


41 PPFD

$\uparrow \mathrm{Bud}$

for B

burst \%

(11.275 W

个 Bud

$\left.\mathrm{m}^{-2}\right)^{*}, 38: 5$

burst

timing

PPFD for $\mathrm{R}$

(6.978 W

$\mathrm{m}^{-2}$ )* and

41 PPFD

for FR

(6.584 W

$\left.\mathrm{m}^{-2}\right) *$

Using

monochrom

atic LED's.

\begin{tabular}{|c|c|c|c|c|c|c|c|c|}
\hline Strø & $\uparrow U$ & $\uparrow$ Bud & Populus & UV-B advanced time & Supplement & UV-B = & Natural & Natural \\
\hline mme & V-B & burst & tremula & until $100 \%$ bud burst in & al UV-B & $290-$ & photoperiod & temperature \\
\hline et al. & & timing & & male Populus tremula & treatment & $315 \mathrm{~nm}$ & at $62^{\circ} 60^{\prime} \mathrm{N}$, & range at \\
\hline$(201$ & & & & by 0.14 days. & was given & & $29^{\circ} 75^{\prime} \mathrm{E}$. & $62^{\circ} 60^{\prime} \mathrm{N}$ \\
\hline \multirow[t]{9}{*}{ 5) } & & & & & with $+30 \%$ & & & $29^{\circ} 75^{\prime} \mathrm{E}$. \\
\hline & & & & & ambient & & & \\
\hline & & & & & UV-B at & & & \\
\hline & & & & & $62^{\circ} 60^{\prime} \mathrm{N}$ & & & \\
\hline & & & & & $29^{\circ} 75^{\prime} \mathrm{E}$ & & & \\
\hline & & & & & ranging & & & \\
\hline & & & & & from a total & & & \\
\hline & & & & & dose of & & & \\
\hline & & & & & $6 \mathrm{kJm}-2 \mathrm{~d}-1$ & & & \\
\hline
\end{tabular}


to $1 \mathrm{kJm}-2 \mathrm{~d}-$

\section{$1(11.5$}

Wm2 to

$69.4 \mathrm{~W}$

$\left.\mathrm{m}^{-2}\right) *$.

\begin{tabular}{|c|c|c|c|c|c|c|c|c|}
\hline Siva & $\uparrow$ & $=\mathrm{Bud}$ & Populus & UV-B did not advance & Supplement & UV-B = & Natural & Natural \\
\hline dasa & UV- & burst & tremula & bud burst in second and & al UV-B & $290-$ & photoperiod & temperature \\
\hline $\mathrm{n}$ et & B & timing & & third year of UV-B & treatment & $315 \mathrm{~nm}$ & at $62^{\circ} 60^{\prime} \mathrm{N}$, & range at \\
\hline al. & & & & treatment in Populus & was given & & $29^{\circ} 75^{\prime} \mathrm{E}$ & $62^{\circ} 60^{\prime} \mathrm{N}$ \\
\hline$(201$ & & & & tremula. & with $+30 \%$ & & & $29^{\circ} 75^{\prime} \mathrm{E}$ \\
\hline \multirow[t]{4}{*}{ 7) } & & & & Continuation of the & ambient & & & \\
\hline & & & & study conducted by & UV-B at & & & \\
\hline & & & & Strømme et al. (2015). & $62^{\circ} 60^{\prime} \mathrm{N}$ & & & \\
\hline & & & & & $29^{\circ} 75^{\prime} \mathrm{E}$ & & & \\
\hline Strø & $\downarrow$ & $=$ Bud & Populus & Attenuation of ambient & UV-B & UV-B = & & \\
\hline mme & UV- & burst & tremula & UV-B along an & ranged from & $290-$ & & \\
\hline et al. & B + & timing & & altitudinal gradient had & $1.4 \mathrm{~W} \mathrm{~m}^{-2}$ & $315 \mathrm{~nm}$ & & \\
\hline$(201$ & altitu & & & no effect on bud burst. & to $0.2 \mathrm{~W}$ & & & \\
\hline \multirow[t]{3}{*}{ 8) } & dinal & & & & $\mathrm{m}^{-2}$ & & & \\
\hline & gradi & & & & & & & \\
\hline & ent & & & & & & & \\
\hline ffren & 个 & $\sim$ Bud burst & Acer & Light pollution had no & Range of & No & Natural & Natural \\
\hline ch- & night & timing & pseudo & significant effect on the & typical & spectra & photoperiod & temperature \\
\hline Cons & light & & platanu & earlier successional & irradiances & for lamp & across UK & across UK \\
\hline $\operatorname{tant}$ & & & $s$ & A.pseuodplatanus, but & coming & provided & sites. & sites. \\
\hline et al. & & & Fagus & advanced bud burst in & from street & in this & & \\
\hline$(201$ & & & sylvatic & the later successional & lamps & study. & & \\
\hline 6) & & & $a$, & Fagus sylvatica, & provided in & Typical & & \\
\hline
\end{tabular}




\begin{tabular}{|c|c|c|c|}
\hline Fraxinu & Fraxinus excelsior, and & Bennie et & street \\
\hline$s$ & Quercus robur. Largest & al. (2016). & lamp \\
\hline excelsio & effects reported in & At $11 \mathrm{~m}$ & spectra \\
\hline$r$ & F.excelsior, where the & ground & provided \\
\hline Quercu & brightest areas advanced & $4800 \mathrm{~lx}$ & in Bennie \\
\hline \multirow[t]{5}{*}{ s robur. } & bud burst by 7.5 days. & $(14.47 \mathrm{~W}$ & et al. \\
\hline & & $\left.\mathrm{m}^{-2}\right)^{*}$, and & (2016). \\
\hline & & 0m ground & \\
\hline & & $30 \mathrm{~lx}(9.045$ & \\
\hline & & $\left(\mathrm{m} \mathrm{m}^{-2}\right)^{*}$. & \\
\hline
\end{tabular}

$1181 *: \mathrm{W} \mathrm{m}^{-2}$ calculated using photobiology package in $\mathrm{R}$.

1182 个: Increase in the light treatment (column“Test(s)"), or increase/advance in bud burst (column "Process").

$1183 \downarrow$ : Decrease in the light treatment (column“Test(s)"), or decrease/delay in bud burst (column "Process").

$1184 \sim$ : Interactive effect between treatments

$1185=:$ No effect of treatment(s) 
1192 Table 2: Breakdown of studies investigating the effects of spectral composition on bud set and leaf senescence 1193 in autumn Studies are separated according to the regions of solar radiation they considered, either R/FR, blue 1194 light, or UV radiation. To allow a comparison of the different irradiances used in different studies, we give both 1195 the original units from each study and an estimate of irradiance following standardisation to energy irradiance in $1196 \mathrm{~W} \mathrm{~m}^{-2}$. Units were converted to $\mathrm{W} \mathrm{m}^{-2}$ based on the spectra provided in the studies, and using the photobiology 1197 package in R (Aphalo, Pedro J., ed., 2013-2018, www.r4photobiology.info ISSN 2343-3248, Helsinki; Aphalo 1198 2015).

\begin{tabular}{|c|c|c|c|c|c|c|c|c|}
\hline $\begin{array}{c}\text { Stud } \\
\mathbf{y}\end{array}$ & Test(s) & Process & $\begin{array}{c}\text { Specie } \\
\text { s }\end{array}$ & $\begin{array}{c}\text { Biological significance } \\
\text { (Effect size) }\end{array}$ & Irradiance & $\begin{array}{c}\text { Spectru } \\
\text { m }\end{array}$ & $\begin{array}{c}\text { Photoperio } \\
\text { d }\end{array}$ & $\begin{array}{c}\text { Temperatu } \\
\text { re }\end{array}$ \\
\hline Lee & 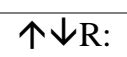 & $=$ Senesce & Cornus & Authors don't report any & Spectrum & R:FR & Natural & Ambient \\
\hline et al. & FR & nce & alternif & changes in phenological & for shade & defined & photoperiod & temperature \\
\hline$(2003$ & & & olia, & dates of leaf fall in & cloth not & as & at $42^{\circ} 32^{\prime} \mathrm{N}$, & at $42^{\circ} 32^{\prime} \mathrm{N}$, \\
\hline \multirow[t]{15}{*}{ ) } & & & Acer & autumn, but rather the & given. & $660: 730 n$ & $72^{\circ} 11^{\prime} \mathrm{W}$ & $72^{\circ} 11^{\prime} \mathrm{W}$ \\
\hline & & & rubru & pigment degradation, & Conducted & $\mathrm{m}$ & & \\
\hline & & $=$ Senesce & $m$, & which forms an & at three & (Methods & & \\
\hline & & nce & Acer & important part of the & different & Followin & & \\
\hline & & & saccha & process. & irradiances & $\mathrm{g}$ Lee et & & \\
\hline & & & rum, & & of $92.4 \%$ of & al. 1996). & & \\
\hline & & & Querc & In situ R:FR treatments & solar PAR, & & & \\
\hline & & & us & of $1.15,0.25$, and shade & $18 \%$ of & & & \\
\hline & & & rubra, & cloth. Shading retarded & solar PAR, & & & \\
\hline & & & Viburn & anthocyanin in 5 out of 6 & and $3 \%$ of & & & \\
\hline & & & $u m$ & species, and retarded & solar PAR. & & & \\
\hline & & & alnifoli & chlorophyll loss in all 6 & & & & \\
\hline & & & $u m$ and & during autumn. Reduced & & & & \\
\hline & & & Fagus & $\mathrm{R}$ and FR had no effect. & & & & \\
\hline & & & grandif & & & & & \\
\hline
\end{tabular}




\begin{tabular}{|c|c|c|c|c|c|c|c|c|}
\hline \multirow{2}{*}{$\begin{array}{l}\text { Tsege } \\
\text { y et }\end{array}$} & \multirow{2}{*}{$\begin{array}{c}\uparrow \downarrow R: \\
\text { FR }\end{array}$} & \multirow{2}{*}{$\begin{array}{l}=\text { growth } \\
\text { cessation }\end{array}$} & \multirow{2}{*}{$\begin{array}{l}\text { Betula } \\
\text { pendul }\end{array}$} & \multirow{2}{*}{$\begin{array}{l}\text { Demonstrated in } \\
\text { ecotypes from southern }\end{array}$} & \multirow{2}{*}{$\begin{array}{l}110 \text { PPFD } \\
\text { PAR with }\end{array}$} & \multirow{2}{*}{$\begin{array}{l}\operatorname{Red} \lambda= \\
667 \mathrm{~nm}\end{array}$} & \multirow{2}{*}{$\begin{array}{l}24 \text { hour } \\
\text { photoperiod }\end{array}$} & $18^{\circ} \mathrm{C}$. \\
\hline & & & & & & & & \\
\hline al. & & & $a$ & Norway $\left(59^{\circ} \mathrm{N}\right)$, the & Phillips & $\operatorname{FR} \lambda=$ & . & \\
\hline$(2005$ & & & & middle of Norway & TLD 58/840 & $739 \mathrm{~nm}$ & & \\
\hline \multirow[t]{19}{*}{)} & & & & $\left(64^{\circ} \mathrm{N}\right)$ and northern & for 12 & & & \\
\hline & & & & Norway $\left(67^{\circ} \mathrm{N}\right)$. & hours. 12 & & & \\
\hline & & & & & hours day & & & \\
\hline & & & & $\mathrm{R}: F R$ day light extension & extension & & & \\
\hline & & & & does not prevent growth & (to provide & & & \\
\hline & & & & cessation in different & 24 hours in & & & \\
\hline & & & & ecotypes of B.pendula & total) with & & & \\
\hline & & & & & either & & & \\
\hline & & & & & monochrom & & & \\
\hline & & & & & atic $\mathrm{R}$ or $\mathrm{FR}$ & & & \\
\hline & & & & & at & & & \\
\hline & & & & & intensities & & & \\
\hline & & & & & of $0.5,1$ & & & \\
\hline & & & & & 9.5 , and 25 & & & \\
\hline & & & & & PPFD & & & \\
\hline & & & & & $(0.09 / 0.08$ & & & \\
\hline & & & & & $0.17 / 0.16$ & & & \\
\hline & & & & & $1.7 / 1.5$ & & & \\
\hline & & & & & $4.4 / 4.0 \mathrm{~W}$ & & & \\
\hline
\end{tabular}




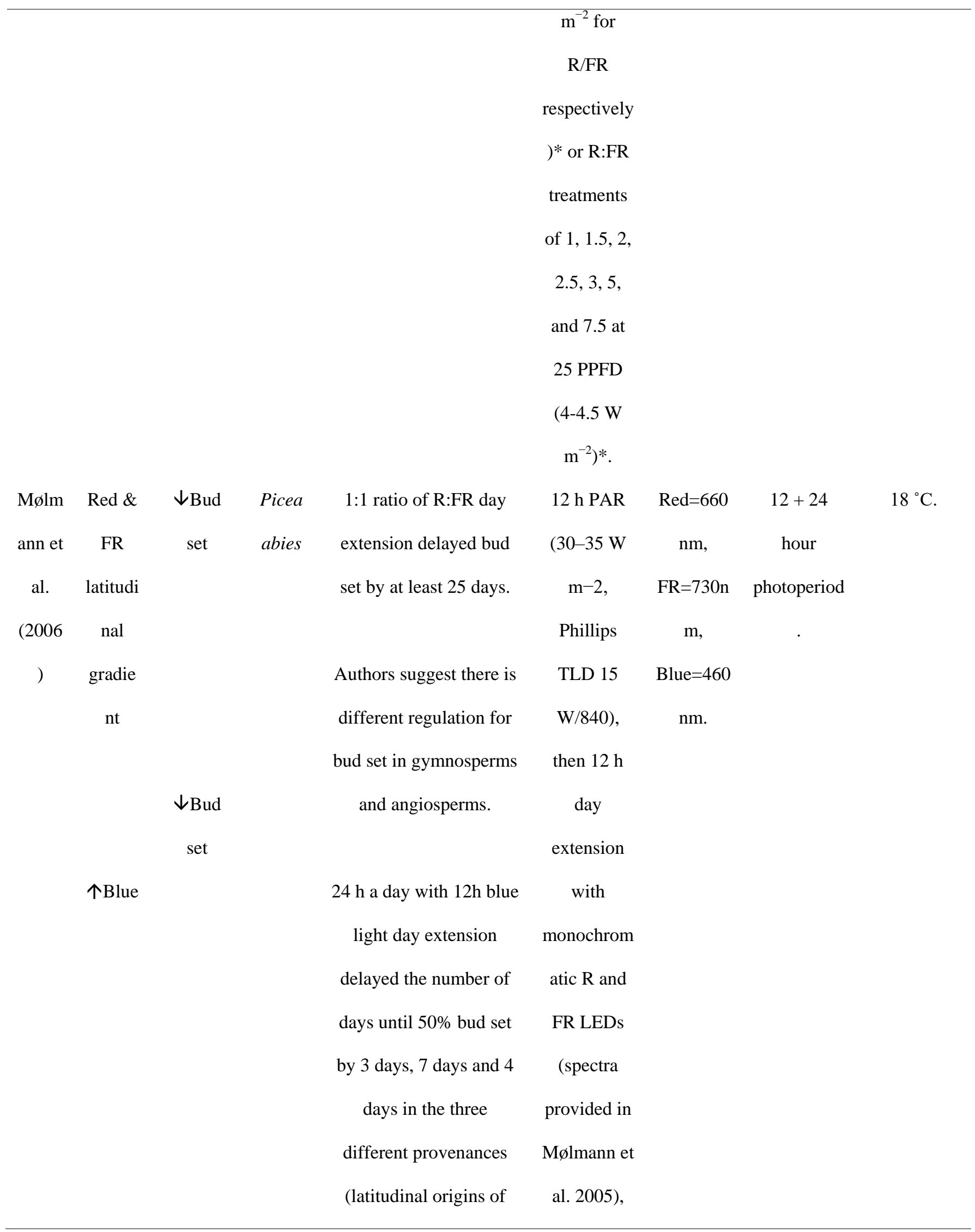




\begin{tabular}{|c|c|c|c|c|c|c|c|c|}
\hline & & & & $59^{\circ}, 64^{\circ}$, and $69^{\circ}$ & with & & & \\
\hline & & & & respectively), but only & treatments & & & \\
\hline & & & & delayed the time until & of either & & & \\
\hline & & & & $100 \%$ bud set by 7 days & $0.1,0.2$ or & & & \\
\hline & & & & in the southern & $0.7 \mathrm{~W} \mathrm{~m}^{-2}$ & & & \\
\hline & & & & provenance $\left(59^{\circ}\right)$ & & & & \\
\hline & & & & Northern populations & Blue light & & & \\
\hline & & & & require higher irradiance & treatment & & & \\
\hline & & & & of monochromatic FR & was $12 \mathrm{~h}$ & & & \\
\hline & & & & and $\mathrm{R}$ light than & PAR 30-35 & & & \\
\hline & & & & southern populations to & $\mathrm{W} \mathrm{m}^{-2}$,with & & & \\
\hline & & & & prevent bud set. & 12 hour day & & & \\
\hline & & & & & extension & & & \\
\hline & & & & & with & & & \\
\hline & & & & & monochrom & & & \\
\hline & & & & & atic BL (1.5 & & & \\
\hline & & & & & $\left.\mathrm{W} \mathrm{\textrm {m } ^ { - 2 }}\right)^{*}$. & & & \\
\hline Opset & 个FR & $\downarrow$ Bud & Picea & FR delays bud set, BL & $12 \mathrm{~h}$ PAR & Red $=660$ & $12+24$ & $18^{\circ} \mathrm{C}$. \\
\hline$h$ et & & set & abies & advances bud set more & $\left(35 \mathrm{~W} \mathrm{~m}^{-2}\right.$ & $\mathrm{nm}$, & hour & \\
\hline al. & & & & than red light in P.abies. & Phillips & $\mathrm{FR}=730 \mathrm{n}$ & photoperiod & \\
\hline$(2016$ & & & & & TLD 15 & $\mathrm{~m}$, & . & \\
\hline ) & $\uparrow R e d$ & & & BL induced $100 \%$ bud & $\mathrm{W} / 840)^{*}$ & Blue $=460$ & & \\
\hline & & $\downarrow$ Bud & & set in three provenances, & & $\mathrm{nm}$. & & \\
\hline & & set & & and red light only & $\mathrm{B}, \mathrm{R}$ or $\mathrm{FR}$ & & & \\
\hline & & & & induced $100 \%$ bud set in & over 24 & & & \\
\hline & 个Blue & & & two provenances, after & hour period & & & \\
\hline & & & & 42 days. & $3.3 \mathrm{~W} \mathrm{~m}^{-2}$ & & & \\
\hline & & 个Bud & & & & & & \\
\hline
\end{tabular}


set

$$
\begin{aligned}
& \text { All provenances showed } \\
& \text { close to } 30 \% \text { more } \\
& \text { growth with FR day } \\
& \text { extension in comparison } \\
& \text { to R:FR day extension } \\
& \text { Expression of CRY and } \\
& \text { PHY light receptor } \\
& \text { genes increased after } \\
& \text { bud set. }
\end{aligned}
$$

\begin{tabular}{|c|c|c|c|c|c|c|c|c|}
\hline Chian & 个FR & $\downarrow$ Bud & Abies & The bud set was less & $12 \mathrm{~h}$ high & Red $=660$ & $12+24$ & $18^{\circ} \mathrm{C}$ and \\
\hline g et & & set & lasioca & developed in trees & pressure & $\mathrm{nm}$, & hour & $24{ }^{\circ} \mathrm{C}$ \\
\hline al. & & & $r p a$ & grown with $12 \mathrm{~h}$ FR day & sodium & $\mathrm{FR}=730 \mathrm{n}$ & photoperiod & \\
\hline$(2018$ & & & (Hook. & extension, in comparison & lamo ( & $\mathrm{m}$ & . & \\
\hline ) & $\uparrow R e d$ & & ) & to $12 \mathrm{~h}$ short-day & Lucalox & Blue $=460$ & & \\
\hline & & $=$ Bud-set & & conditions without light & $400 \mathrm{~W}$ & $\mathrm{~nm}$. & & \\
\hline & & & & extension. Blue and Red & General & & & \\
\hline & & & & light treatments with day & electric, & & & \\
\hline & 个Blue & & & extension did not show & New York, & & & \\
\hline & & $=$ Bud-set & & any significant & NY, & & & \\
\hline & & & & difference from $12 \mathrm{~h}$ & USA).at & & & \\
\hline & & & & short-day conditions. & 160 PPFD & & & \\
\hline & & & & & $(32.16 \mathrm{~W}$ & & & \\
\hline Juntil & 个Blue & $=$ growth & Salix & Growth cessation and & $12-20 h$ & $\operatorname{Red}=660$ & $12-20 \mathrm{~h}$ & $18{ }^{\circ} \mathrm{C}$. \\
\hline la and & $+\mathrm{R}: \mathrm{FR}$ & cessation & pentan & bud set of northern & photoperiod & $\mathrm{nm}$. & photoperiod & \\
\hline Kauri & latitudi & & $d r a$ & ecotype S.pentandra was & treatment & $\mathrm{FR}=730 \mathrm{n}$ & & \\
\hline $\mathrm{n}$ & nal & & & more sensitive to & consisting & $\mathrm{m}$. & & \\
\hline
\end{tabular}




\begin{tabular}{|c|c|c|c|c|c|c|c|c|}
\hline$(1985$ & gradie & & & different treatments of & white light & $\mathrm{W}=400-$ & & \\
\hline \multirow[t]{13}{*}{ ) } & $\mathrm{nt}$ & & & spectral composition, & and a 15 & $700 \mathrm{~nm}$ & & \\
\hline & & & & whereas southern & minute end & and blue & & \\
\hline & & & & ecotype was more & of day & undefine & & \\
\hline & & & & sensitive to changes in & treatment & d. & & \\
\hline & & & & photoperiod. End of day & with either & & & \\
\hline & & & & treatment with FR was & $\mathrm{R}(6 \mathrm{~W}$ & & & \\
\hline & & & & most effective at & $\mathrm{m}^{-2}$ ) or FR & & & \\
\hline & & & & delaying growth & light $(0.2 \mathrm{~W}$ & & & \\
\hline & & & & cessation, white $+\mathrm{BL}$ & $\left.\mathrm{m}^{-2}\right)$. In $\mathrm{a}$ & & & \\
\hline & & & & had an intermediate & separate & & & \\
\hline & & & & effect, and R light & experiment, & & & \\
\hline & & & & delayed the least. & $\mathrm{W}$ light $=$ & & & \\
\hline & & & & & $\sim 20 \mathrm{~W} \mathrm{~m}^{-2}$ & & & \\
\hline Meng & 个Blue & 个Senesc & Glycin & BL advances leaf & White light & Blue $\lambda=$ & Long day & 25 to $\sim 28^{\circ} \mathrm{C}$ \\
\hline et & & ence & $e \max$ & senescence in via & as 200 to & $436 \mathrm{~nm}$ & photoperiod & \\
\hline al. $(20$ & & & & $C R Y 2 a$. & 300 PPFD & $\operatorname{Red} \lambda=$ & as $16 \mathrm{~h}$ light & \\
\hline \multirow[t]{9}{*}{ 13) } & & & & CRY2a mutants had & $(43.6-65.4$ & $658 \mathrm{~nm}$ & and $8 \mathrm{~h}$ dark, & \\
\hline & & & & increased chlorophyll & $\left.\mathrm{W} \mathrm{m}^{-2}\right)^{*}$ & & and & \\
\hline & & & & content measured at 3,6 & however no & & continuous & \\
\hline & & & & and 8.5 weeks after & details on & & illumination & \\
\hline & & & & sewing, grown under & irradiance & & as $24 \mathrm{~h}$ light. & \\
\hline & & & & long day photoperiods & of blue and & & & \\
\hline & & & & and continuous & red & & & \\
\hline & & & & illumination. & irradiance & & & \\
\hline & & & & & given. & & & \\
\hline Strøm & 个UV- & 个Bud & Populu & UV-B advanced time & Supplement & UV-B = & Natural & Natural \\
\hline me et & B & set & $s$ & until $100 \%$ bud set in & al UV-B & 290- & photoperiod & temperature \\
\hline
\end{tabular}




\begin{tabular}{|c|c|c|c|c|c|c|c|c|}
\hline al. & & & tremul & both males and females, & treatment & $315 \mathrm{~nm}$ & at $62^{\circ} 60^{\prime} \mathrm{N}$, & range at \\
\hline$(2015$ & & & $a$ & by an average of 1 day. & was given & & $29^{\circ} 75^{\prime} \mathrm{E}$. & $62^{\circ} 60^{\prime} \mathrm{N}$ \\
\hline ) & & & & & with $+30 \%$ & & & $29^{\circ} 75^{\prime} \mathrm{E}$. \\
\hline & & & & & ambient & & & \\
\hline & & & & & UV-B at & & & \\
\hline & & & & & $62^{\circ} 60^{\prime} \mathrm{N}$ & & & \\
\hline & & & & & $29^{\circ} 75^{\prime} \mathrm{E}$ & & & \\
\hline & & & & & ranging & & & \\
\hline & & & & & from a dose & & & \\
\hline & & & & & of $6 \mathrm{kJm}-2 \mathrm{~d}-$ & & & \\
\hline & & & & & 1 to $1 \mathrm{kJm}-$ & & & \\
\hline & & & & & 2d-1 (11.5 & & & \\
\hline & & & & & $\mathrm{W} \mathrm{m} \mathrm{m}^{-2}$ to & & & \\
\hline & & & & & $69.4 \mathrm{~W}$ & & & \\
\hline & & & & & $\left.\mathrm{m}^{-2}\right)^{*}$. & & & \\
\hline Sivad & 个UV- & $=$ Bud set & Populu & UV-B does not advance & Supplement & UV-B = & Natural & Natural \\
\hline asan & $\mathrm{B}$ & & $s$ & bud set in years 2 and 3 & al UV-B & $290-$ & photoperiod & temperature \\
\hline et al. & & & tremul & of treatment in Populus & treatment & $315 \mathrm{~nm}$ & at $62^{\circ} 60^{\prime} \mathrm{N}$, & range at \\
\hline$(2017$ & & & $a$ & tremula & was given & & $29^{\circ} 75^{\prime} \mathrm{E}$. & $62^{\circ} 60^{\prime} \mathrm{N}$ \\
\hline ) & & & & & with $+30 \%$ & & & $29^{\circ} 75^{\prime} \mathrm{E}$. \\
\hline & & & & Continuation of the & ambient & & & \\
\hline & & & & study conducted by & UV-B at & & & \\
\hline & & & & Strømme et al. (2015). & $62^{\circ} 60^{\prime} \mathrm{N}$ & & & \\
\hline & & & & & $29^{\circ} 75^{\prime} \mathrm{E}$. & & & \\
\hline Strøm & $\downarrow U V-$ & $\sim$ Bud set & Populu & Attenuation of UV-B & UV-B & UV-B = & Natural & Natural \\
\hline me et & $\mathrm{B}+$ & & $s$ & delayed bud set at high & ranged from & $290-$ & photoperiod & temperature \\
\hline al. & altitudi & & tremul & altitude, but not at low & $1.4 \mathrm{~W} \mathrm{~m}^{-2}$ & $315 \mathrm{~nm}$ & at $61^{\circ} 27^{\prime} \mathrm{N}$ & range at \\
\hline$(2018$ & nal & & $a$ & altitude. & to $0.2 \mathrm{~W}$ & & $10^{\circ} 11^{\prime} \mathrm{E}$. & $61^{\circ} 27^{\prime} \mathrm{N}$ \\
\hline
\end{tabular}




\begin{tabular}{|c|c|c|c|c|c|c|c|c|}
\hline ) & gradie & & & & $\mathrm{m}^{-2}$ & & & $10^{\circ} 11^{\prime} \mathrm{E}$. \\
\hline Zueth & 个UV- & $\uparrow$ Leaf & Fagus & Supplementary UV-B & UV-B & UV-B = & Natural & Natural \\
\hline en et & $\mathrm{B}$ & senescen & sylvati & radiation from a lamp & treatment & $280-$ & photoperiod & temperature \\
\hline al. & & ce & $c a$ & advanced final leaf & provided & $320 \mathrm{~nm}$ & at & range at \\
\hline$(1997$ & & & & senescence by 12 days. & under $15 \%$ & & $55^{\circ} 4^{\prime} \mathrm{N}$ & $55^{\circ} 4^{\prime} \mathrm{N}$ \\
\hline ) & & & & & ozone & & $12^{\circ} 06^{\prime} \mathrm{E}$ & $12^{\circ} 06^{\prime} \mathrm{E}$ \\
\hline & & & & & depletion, & & & \\
\hline & & & & & with & & & \\
\hline & & & & & ambient & & & \\
\hline & & & & & treatments & & & \\
\hline & & & & & ranging & & & \\
\hline & & & & & from $6.9-$ & & & \\
\hline & & & & & $2.29 \mathrm{~W} \mathrm{~m}^{-2}$ & & & \\
\hline & & & & & from Sep- & & & \\
\hline & & & & & July and & & & \\
\hline & & & & & UV-B & & & \\
\hline & & & & & treatment & & & \\
\hline & & & & & ranging & & & \\
\hline & & & & & from an & & & \\
\hline & & & & & additional + & & & \\
\hline & & & & & $1.7-0.58 \mathrm{~W}$ & & & \\
\hline & & & & & $\mathrm{m}^{-2}$. & & & \\
\hline Matz & $\uparrow$ & $\downarrow$ Leaf & Populu & Street lamp light delays & Light & No & Natural & Natural \\
\hline ke & night & senescen & $s$ & leaf fall in tree species in & intensity & spectra & photoperiod & temperature \\
\hline (1936 & light & ce & canadi & New York, USA. & from street & available & in New & range in \\
\hline \multirow[t]{2}{*}{ ) } & & & ensis, & & lamps & for the & York, USA. & New York, \\
\hline & & & Platan & Leaves on trees facing & varied from & street & & USA. \\
\hline
\end{tabular}




\begin{tabular}{|c|c|c|c|c|c|c|c|c|}
\hline & & & us & the street lamp fell at & $1-2$ foot & lamps. & & \\
\hline & & & occide & least one month later in & candles at & Street & & \\
\hline & & & ntalis, & comparison to leaves & the tips of & lamps & & \\
\hline & & & Salix & facing the other side. & branches & ranged & & \\
\hline & & & fragilis & & $(0.017-$ & from 76 & & \\
\hline & & & . & & $0.032 \mathrm{~W}$ & W 11- & & \\
\hline & & & & & $\left.\mathrm{m}^{-2}\right)^{*}$ & volt bulb & & \\
\hline & & & & & & to a 200 & & \\
\hline & & & & & & Watt & & \\
\hline & & & & & & 120 -volt & & \\
\hline & & & & & & bulb. & & \\
\hline Saral & $\uparrow$ & $=$ Leaf & B.pend & Street lamp light does & $250 \mathrm{~W}$ high & No & Natural & Natural \\
\hline a et & night & senescen & ula & not delay autumn leaf & pressure & spectra & photoperiod & temperature \\
\hline al. & light & ce & & colouration in & mercury & available. & at $65^{\circ} 00^{\prime \prime} \mathrm{N}$ & range at \\
\hline$(2013$ & & & & B.pendula. & lamps, & Red $=$ & $25^{\circ} 27^{\prime \prime E}$ & $65^{\circ} 00^{\prime \prime} \mathrm{N}$ \\
\hline \multirow[t]{13}{*}{)} & & & & & KolorluxT & $655-665$ & & $25^{\circ} 27^{\prime \prime} \mathrm{E}$. \\
\hline & & & & & $\mathrm{M}$ & $\mathrm{nm}$ & & \\
\hline & & & & & General & $\mathrm{FR}=$ & & \\
\hline & & & & & Electrics, & $725-$ & & \\
\hline & & & & & New York, & $735 \mathrm{~nm}$ & & \\
\hline & & & & & USA. & & & \\
\hline & & & & & Conducted & & & \\
\hline & & & & & under low & & & \\
\hline & & & & & irradiance & & & \\
\hline & & & & & street lamps & & & \\
\hline & & & & & (1.3 PPFD & & & \\
\hline & & & & & $1 \mathrm{~m}$ down & & & \\
\hline & & & & & from lamp, & & & \\
\hline
\end{tabular}




\begin{tabular}{|c|c|c|c|c|c|c|c|c|}
\hline & & & & & $1.3 \mathrm{~W}$ & & & \\
\hline & & & & & $\mathrm{m}^{-2}$ )* with & & & \\
\hline & & & & & low & & & \\
\hline & & & & & irradiance & & & \\
\hline & & & & & of R:FR( & & & \\
\hline & & & & & 0.013PPFD & & & \\
\hline & & & & & $1 \mathrm{~m}$ down & & & \\
\hline & & & & & from lamp, & & & \\
\hline & & & & & $0.003 \mathrm{~W}$ & & & \\
\hline & & & & & $\left.\mathrm{m}^{-2}\right)^{*}$ & & & \\
\hline Mass & $\uparrow$ & $\uparrow$ Leaf & Platan & Trees in 3 areas under & Mean street & No & Natural & Natural \\
\hline etti & night & Senescen & us $x$ & street lamps, had leaf & lamp & spectra & photoperiod & temperature \\
\hline (2018 & light & ce & acerifo & senescence delayed by & irradiance & available. & a $43^{\circ} 77$ "N & range a \\
\hline ) & & & lia & 20 days compared to one & of $12.6 \mathrm{~W}$ & & $11^{\circ} 26^{\prime \prime} \mathrm{E}$ & $43^{\circ} 77 \mathrm{~N}$ \\
\hline & & & & area of trees which were & $\mathrm{m}^{-2}$ & & & $11^{\circ} 26^{\prime \prime E t}$ \\
\hline & & & & not under street lamps. & measured at & & & \\
\hline & & & & & $2 \mathrm{~m}$ height. & & & \\
\hline
\end{tabular}

*:Wm${ }^{2}$ calculated using photobiology package in $\mathrm{R}$.

$1200 \uparrow:$ Increase in the light treatment (column“Test(s)"), or increase/advance in bud set or leaf senescence (column 1201 "Process").

$1202 \downarrow$ : Decrease in the light treatment (column“Test(s)"), or decrease/delay in bud set or leaf senescence (column 1203 "Process").

$1204 \sim$ : Interactive effect between treatments

$1205=:$ No effect of treatment $\underline{(\mathrm{s})}$ 
Table 3 The mean ( \pm 1 SE) and median ( \pm inter-quartile range) effect sizes and treatment sizes reported in experimental studies investigating the influence of chilling, forcing temperatures and photoperiod on the bud burst of tree species. Further details provided in Table S1.

\begin{tabular}{|c|c|c|c|c|c|c|}
\hline \multirow[b]{2}{*}{ Species } & \multicolumn{3}{|c|}{ Mean bud burst } & \multicolumn{3}{|c|}{ Median bud burst } \\
\hline & $\begin{array}{c}\text { Days } \\
\text { advanced per } \\
1 \text { chilling day } \\
\text { increase }\end{array}$ & $\begin{array}{c}\text { Days } \\
\text { advanced } \\
\text { per } \\
\mathbf{1}^{\circ} \mathbf{C} \\
\text { increase } \\
\end{array}$ & $\begin{array}{c}\text { Days advanced } \\
\text { per } \\
1 \mathrm{hr} \\
\text { photoperiod } \\
\text { increase }\end{array}$ & $\begin{array}{c}\text { Days } \\
\text { advanced } \\
\text { per } \\
1 \text { chilling } \\
\text { day } \\
\end{array}$ & $\begin{array}{c}\text { Days } \\
\text { advanced } \\
\text { per } \\
1^{\circ} \mathbf{C} \\
\text { increase } \\
\end{array}$ & $\begin{array}{c}\text { Days advanced } \\
\text { per } \\
1 \text { hr } \\
\text { photoperiod } \\
\text { increase } \\
\end{array}$ \\
\hline $\begin{array}{l}\text { A. } \\
\text { glutino } \\
\text { sa } \\
\text { B. }\end{array}$ & $0.49 \pm 0.11$ & - & $3.22 \pm .36$ & $3.75 \pm 0.43$ & & $3.33 \pm 2.66$ \\
\hline $\begin{array}{c}\text { pendul } \\
a\end{array}$ & $0.35 \pm 0.16$ & $1.52 \pm 0.24$ & $0.66 \pm 0.37$ & $0.14 \pm 0.47$ & $1.94 \pm 1.66$ & $0.0 \pm 3.33$ \\
\hline $\begin{array}{c}P . \\
\text { abies }\end{array}$ & $0.76 \pm 0.13$ & $5.56 \pm 0.84$ & $2.19 \pm 0.85$ & $0.94 \pm 0.59$ & $1.69 \pm 3.95$ & $0.5 \pm 2.04$ \\
\hline $\begin{array}{c}P . \\
\text { tremula }\end{array}$ & $1.75 \pm 0.73$ & $1.88 \pm 0$ & $3.16 \pm 2.61$ & $1.45 \pm 2.04$ & $1.88 \pm 0$ & $1.33 \pm 0$ \\
\hline$\underset{\text { robur }}{Q .}$ & $35.13 \pm 0$ & $7.39 \pm 2.44$ & $0.0 \pm 0$ & $3.55 \pm 0$ & $6.52 \pm 10.78$ & $0.0 \pm 0$ \\
\hline $\begin{array}{l}\text { Mean } \\
\text { effect }\end{array}$ & $1.1 \pm 0.15$ & $2.04 \pm 0.37$ & $2.11 \pm 0.64$ & $0.92 \pm 0.86$ & $1.92 \pm 2.35$ & $0.5 \pm 3.5$ \\
\hline
\end{tabular}


1219 Figure 1. The change in daylength, twilight length and night length throughout the year 2017, along a latitudinal 1220 gradient of locations including Oulu $\left(65.01^{\circ} \mathrm{N}, 25.47^{\circ} \mathrm{E}\right)$, Helsinki $\left(60.17^{\circ} \mathrm{N}, 24.94^{\circ} \mathrm{E}\right)$, and Madrid $\left(40.42^{\circ} \mathrm{N}\right.$,

$12213.70^{\circ} \mathrm{W}$ ), calculated from the photobiology package in R (Aphalo, 2016 ). Twilight length was defined as civil 1222 twilight, including solar angles from $-6^{\circ}$ and $0^{\circ}$.

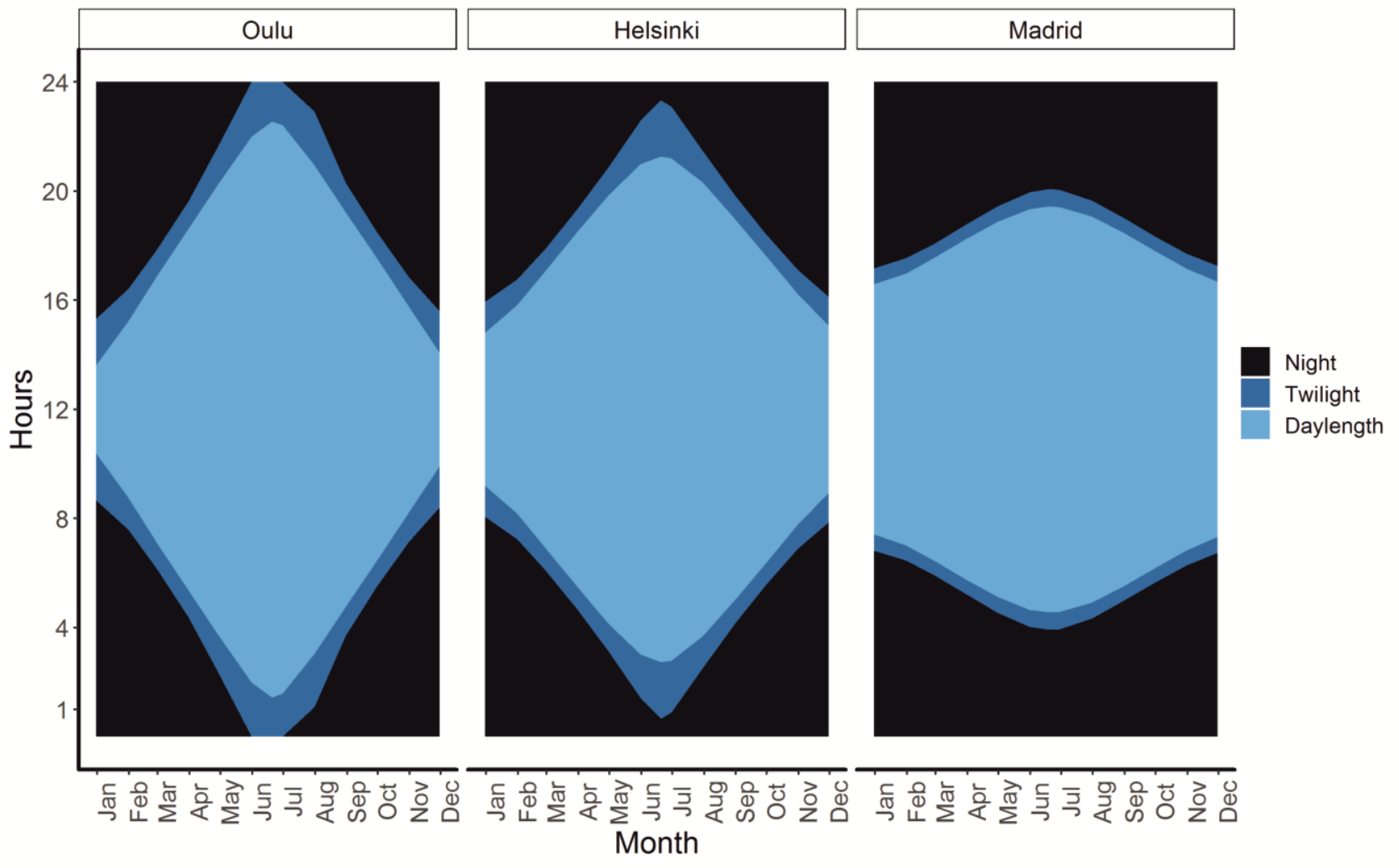


1228 Figure 2. Modelled spectral ratios for B:R and R:FR of incident solar radiation at solar angles of $0^{\circ}$ to $-6^{\circ}$ for 1229 civil twilight, and at solar zenith for noon. Locations along a latitudinal gradient shown in Figure 2.Values are 1230 shown for spring equinox, summer solstice, autumn equinox, and winter solstice. Here B:R defined as (4101231 500/610-700nm, Johnson et al. 1967), R:FR Sellaro as(650 - 670/720 - $740 \mathrm{~nm}$, Sellaro et al. 2010) and R:FR 1232 Smith as ((655 - 665/725 - $735 \mathrm{~nm}$, Smith, 1982). Spectral irradiance was modelled using the radiative transfer 1233 model libRadtran following Emde et al. 2016, Brelsford 2017). Water column data was taken from Kållberg et 1234 al. (2005), ozone column thickness data from Experimental Studies Unit, Environment Canada (http://exp1235 studies.tor.ec.gc.ca/e/index.htm).For twilight values, the solver sdisort was used, and for noon values, the solver 1236 disort was used. Further details provided in SI.

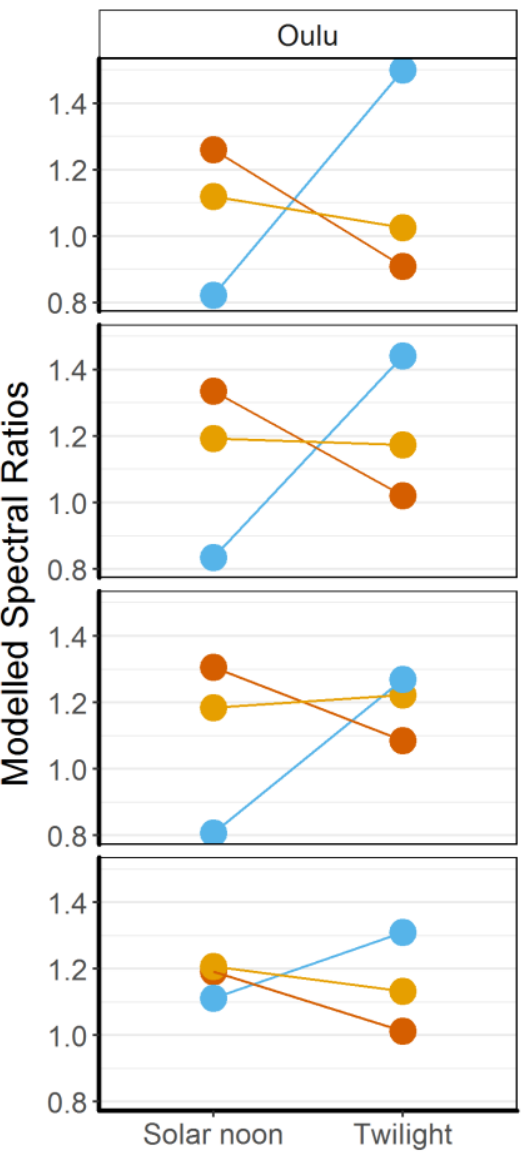

1237
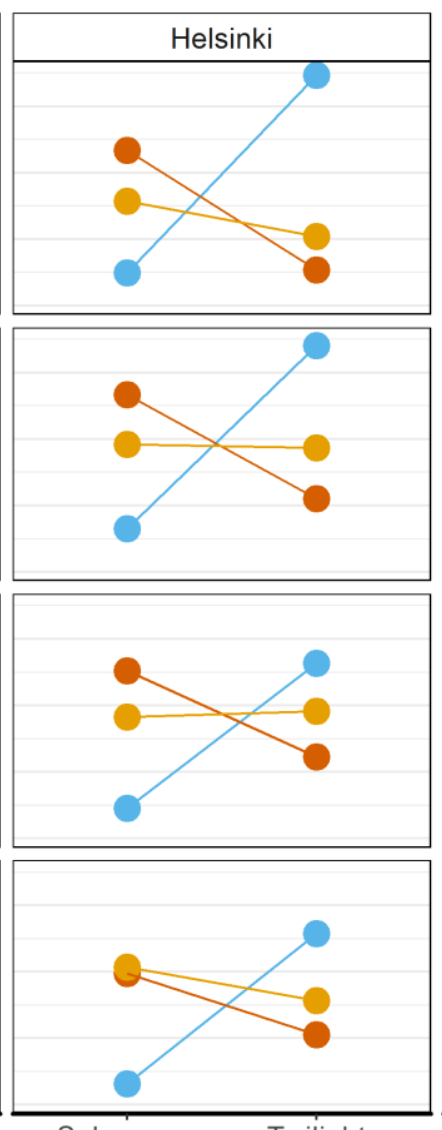

Solar noon Twilight Time of Day
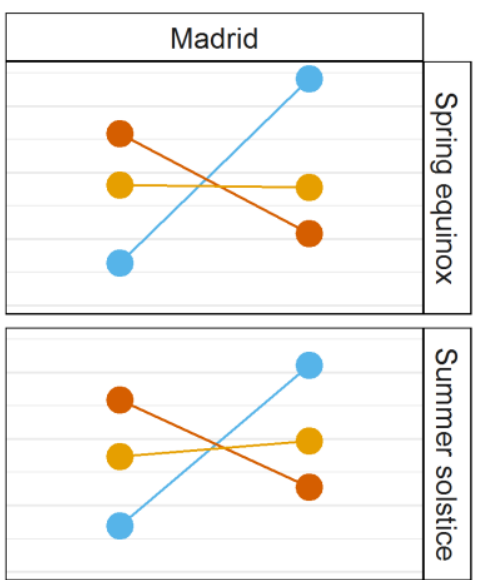

Ratio

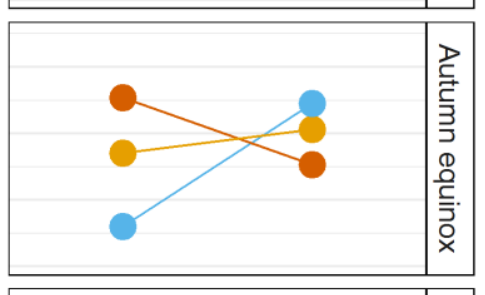

B: $R$

R:FR Sellaro

R:FR Smith 
1240 Figure 3. The modelled spectral photon irradiance for blue light $(420-490 \mathrm{~nm})$ and UV-A radiation (315-

$1241400 \mathrm{~nm}$ ) at the locations given in Figure 2 along a latitudinal gradient. Spectral photon irradiance was modelled 1242 as described in Figure 3. Further details provided in SI.

1243
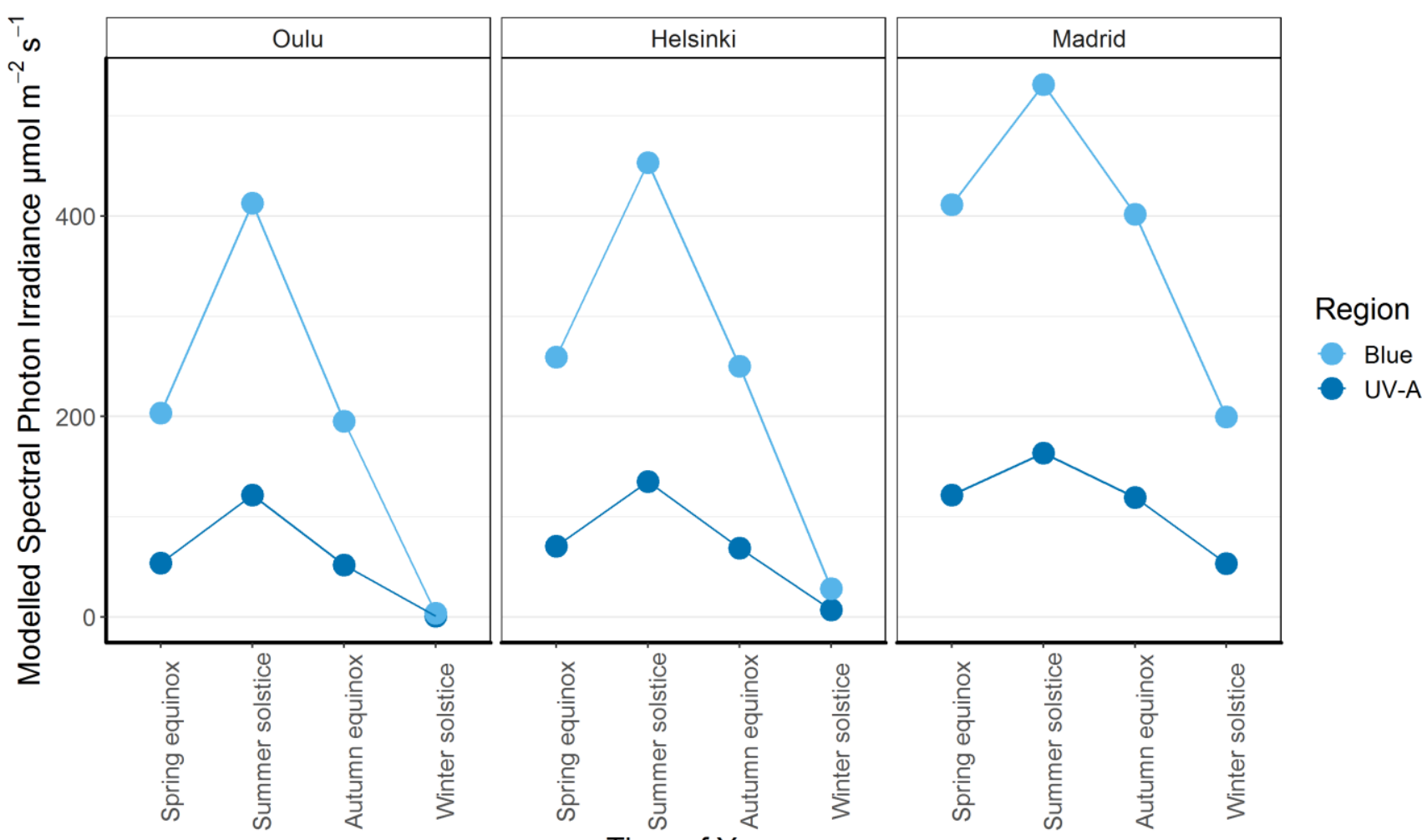

1244
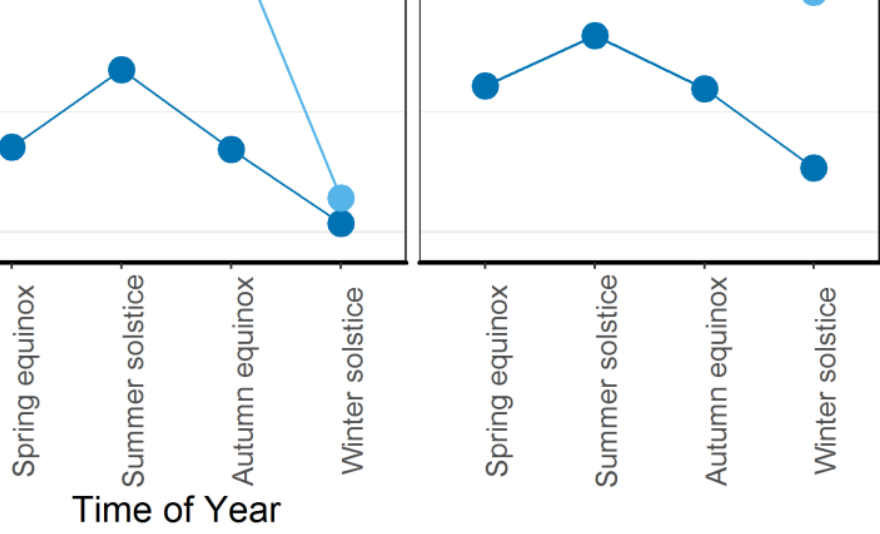

1245

1246

1247

1248 
1249 Figure 4. The modelled spectral irradiance for UV-B $(280-315 \mathrm{~nm})$ at the given locations in Figure 2 across a 1250 latitudinal gradient. Irradiance was simulated using the methods described in Figure 3. Further details provided 1251 in SI.

1252
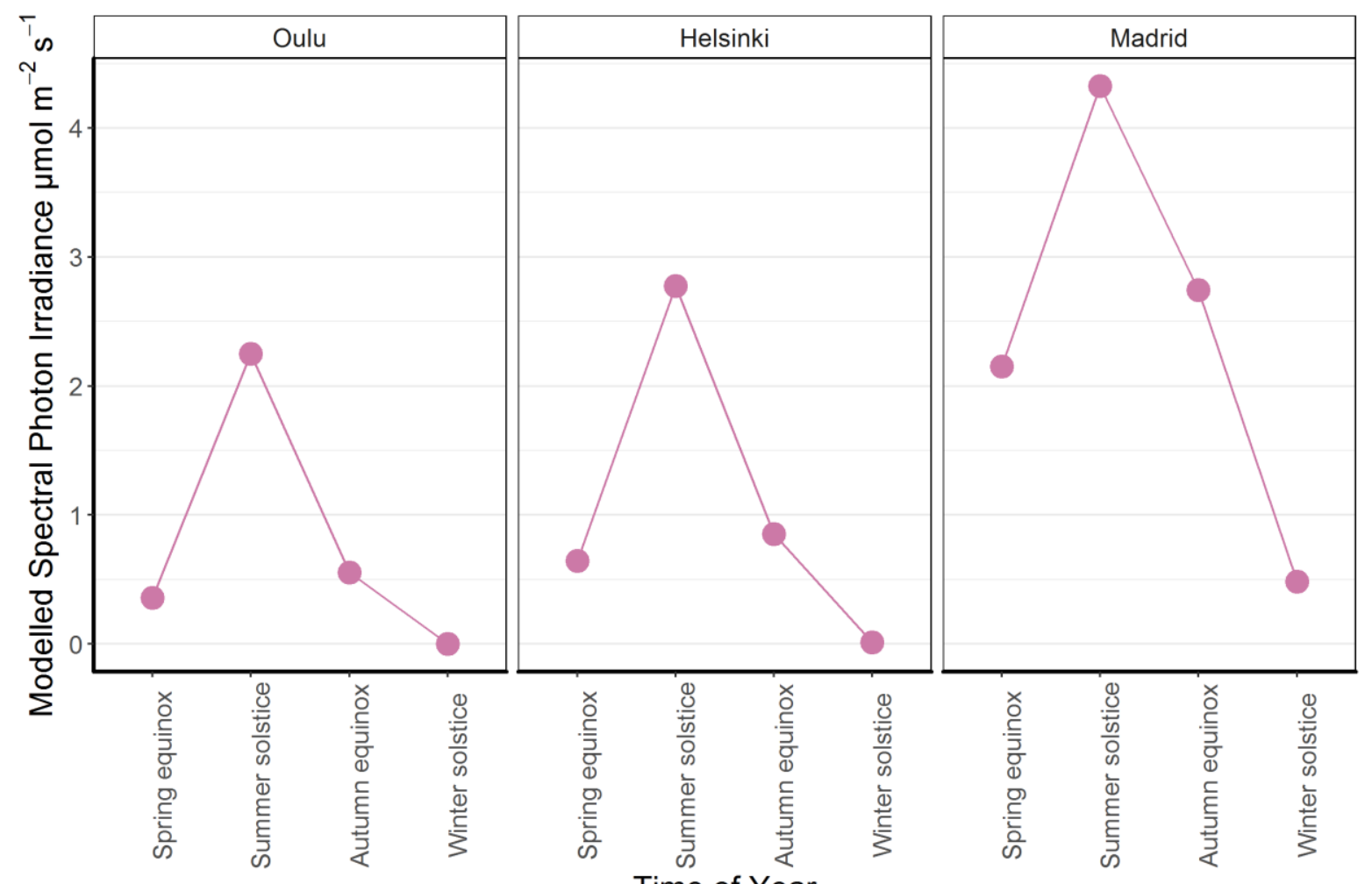

Region

UV-B

1253

Time of Year

1254

1255

1256

1257

1258

1259 
1260 Figure 5. A schematic representing the different environmental cues which can affect (A) spring bud burst and

1261 (B) autumn senescence in tree species, based on mean and median responses in Tables 1 and 2 (Further details in

1262 Tables S1 and S2). For spring bud burst, chilling during dormancy, forcing temperature and light derived cues

1263 such as photoperiod, irradiance and spectral composition can influence spring bud burst. Phytochrome (PHY)

1264 expression can be associated with bud burst (Frewen et al. 2000), although not directly in response to R:FR.

1265 Temperature, photoperiod and spectral composition have been shown to influence bud set and autumn leaf

1266 senescence. Expression of phytochromes (PHYs) and cryptochromes (CRYs) has been shown to increase during

1267 bud set (Frewen et al. 2000, Opseth et al. 2016), suggesting that either twilight or end-of-day (EOD) blue light

1268 may also play a role in regulating bud set.
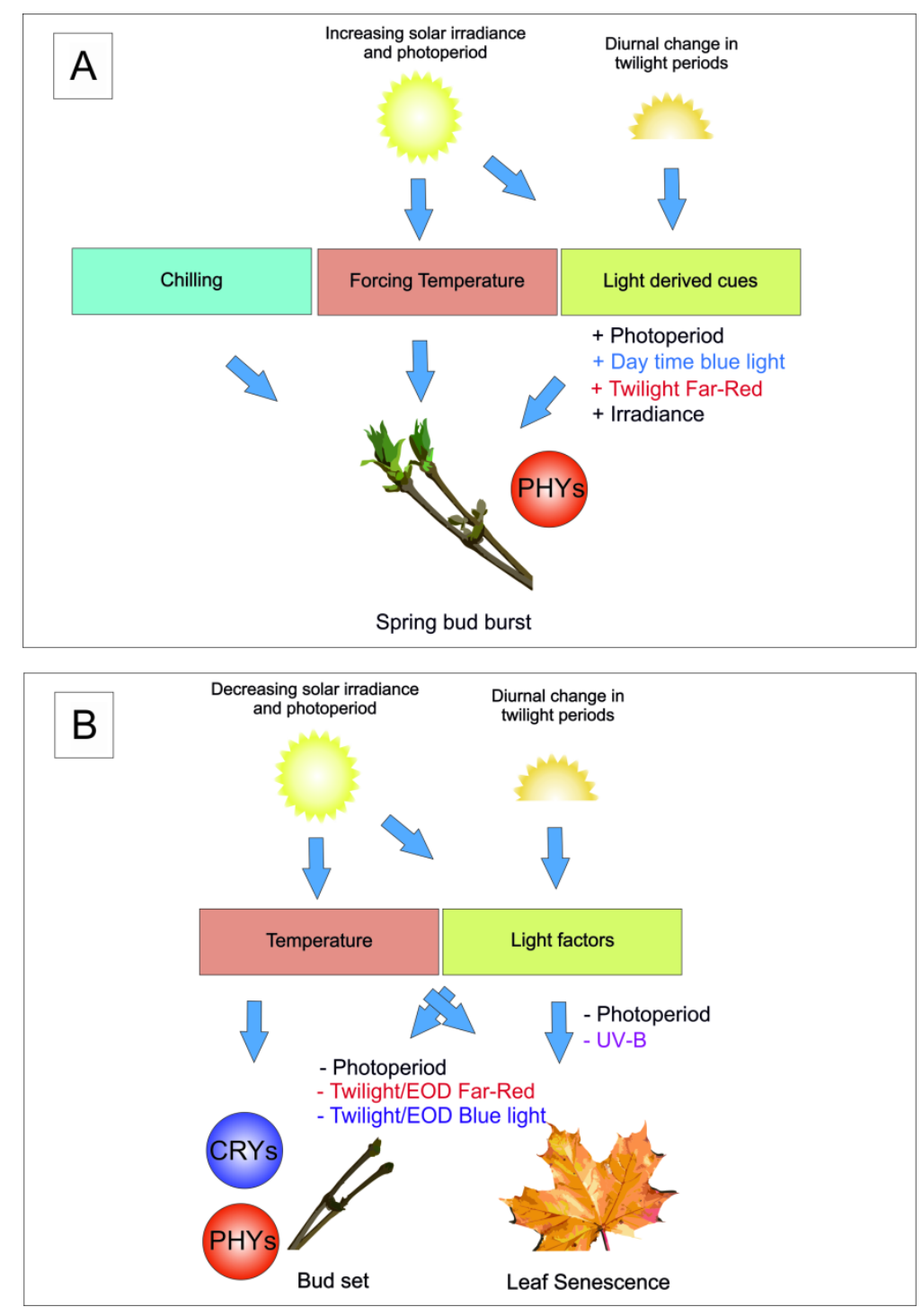